\title{
IMPACT OF SHORT SELLING IN FINANCIAL MARKETS
}

\author{
Neha Sharma* \\ *Research Scholar, Department of Management, Dayalbagh Educational Institute, Dayalbagh, Agra - 282 005, India.
}

\begin{abstract}
With the financial crisis gripping the stock market worldwide in the last few months of 2008, there have been widespread criticisms on the process of short selling. The opponents have questioned the existence of short selling and argued about the foul play of the short selling. Following such widespread campaigning, in order to boost the investors confidence short selling was either or restricted in most of the Western markets and in the Anglo-Saxon countries. Nevertheless, the financial experts and economists were divided in the opinion of banning short selling. Many argued that such ban will affect the market efficiency and disturb the market from operating freely and fairly. Hence the current research is about the impacts or the effects the ban on short selling have on the financial markets, especially the capital markets. This study focuses on finding such effects in a neutralised approach and free from bias to any side. The research is compiled in such a way that, the literature review was conducted with an aim of uncovering the loop holes and functioning of short selling experts. Accordingly, the findings of the literature review are in the form of a list of key characteristics short selling possess which increases the efficiency of the system. These key characteristics are evaluated based on the stock price variations in the LSE. The conclusions are drawn based on the findings on the literature review and the analysis done on the stock price movements, crude oil price variation and a survey on the perception of short selling. Based on the findings, a set of recommendations are made which will help in the further understanding of the short selling.
\end{abstract}

\section{CHAPTER.1 INTRODUCTION}

\section{Introduction}

The recent global financial crisis has reopened one of the controversial debates on financial market: short selling. Though the concept of short selling is as old as the existence of financial market, not many are aware of the exact functioning of short selling in the financial markets. This research study aims to find the facts and myths behind the controversy. The research report is organized into five chapters. The first one being the introduction chapter will discuss about the background, history and the mechanism of short selling. The second chapter is the literature review which will examine the previous research, existing literatures from magazines, books, journals, research papers and other sources. The third chapter will discuss about the research methodology and how the research is organized. Further this chapter explains the types of data and sources of data used in the study. Chapter four will explain the findings, inferences, observations and conclusions of the study. The final chapter will discuss about the outcomes, recommendations and conclusion.

\subsection{Background}

Short Selling is the act of borrowing stock to sell with the expectation of price dropping and the intent of buying the stock back to replace at a cheaper price. There are substantial risks with short selling, some of which can be avoided through education on the process. Short interest is a measure of the total share volume that is currently short the stock. When a person short sells, the order must be identified as a short sale and these statistics are kept for each stock by the exchange. Short interest can be a source of demand if buyers become enthusiastic for the stock and price rises prompting some short sellers to reduce risk by buying back stock to replace and closing the short position. Short sellers borrow shares from a broker and sell them in the market in anticipation that the price will fall. They then buy the shares back at the lower price, returning them to the broker, and profiting on the price decline. The difference is their profit. The natural question is: how can one sell a stock that one does not own? When you sell a stock short, the broker lends you the shares in order to allow delivery to the buyer. Later, when you buy the stock back (otherwise called covering), the broker reacquires the shares, and all is settled. For example, you believe XYZ Corporation stock price is too high, so you instruct your broker to sell short 100 shares at $\$ 50$. The broker borrows 100 shares from another account, who previously approved such an arrangement, and delivers them to the buyer. The proceeds of $\$ 5,000$ from the sales are credited to your account. If the stock were to fall to $\$ 30$, you may then decide to buy it back for $\$ 3,000$ and you make $\$ 2,000$ profit. Of course the stock may go up instead of down. Suppose it goes to $\$ 60$, and you decide to purchase in order to minimize your losses. You buy the shares back and you have lost $\$ 1,000(\$ 5000-\$ 6000)$. In fact, there is little difference from this situation than if you had bought the stock at $\$ 60$ and watched it decline to $\$ 50$. There is no limit on the amount of time you may remain short unless the broker "calls" the stock back because he must return the borrowed shares to the owner for some reason. This is a highly unusual situation, and only occurs with stocks that have a low level of liquidity. There are a few stocks that the broker cannot obtain. In such cases, you may not short that particular stock. In the recent past, especially after the collapse of Lehmann brothers which triggered the financial turmoil has opened a debate regarding the ban of short selling in financial markets. The proponents of short selling advocates that the ban is an effort to manipulate the natural course of the functioning of financial market, whereas the opponents of short selling favour the ban of short selling since it is adding selling pressure on already plummeted stocks(financial instrument). The study aims to explore the hidden advantages of the short selling and the role it plays in stabilizing the market. 


\subsubsection{History of short selling}

The first case of selling short dates back to 1609 and concerns Dutch trader Isaac Le Maire, a big shareholder of the Compagnie (VOC). In 1602, he invested about 85,000 guilders in the VOC. By 1609, the VOC still was not paying dividend, and Le Maire's ships on the Baltic routes were under constant threats of attack by English ships owing to trading conflicts between the British and the VOC. Le Maire decided to sell his shares and sold even more than he had. The notables spoke of an outrageous act and this led to the first real stock exchange regulations: a ban on short selling. The ban was revoked a couple of years later. Short sellers, or "shorts," have been blamed for almost every financial crisis in the 400 years since the Dutch episode. Shorts came under fire after the U.S. stock market crash of 1929, and U.S. President Herbert Hoover condemned short selling in 1932. More recently, shorts were blamed for the U.S. stock market crash of October 1987 and, in 1997, Malaysia charged Credit Lyonnais with short selling after the collapse of the country's currency and stock market. The next year, the New York Fed bailed out Long Term Capital Management to avoid wider market impact from the hedge fund's short positions.

\subsubsection{Controversy of short selling}

Short selling has been a target of ire since at least the eighteenth century when England banned it outright. It was perceived as a magnifying effect in the violent downturn in the Dutch tulip market in the seventeenth century. The term "short" was in use from at least the mid-nineteenth century. It is commonly understood that "short" is used because the short seller is in a deficit position with his brokerage house. Even in good times, short sellers are disdained for betting against the continuing party. But the short sellers say they are only raising flags that stocks are overvalued. Short sellers borrow shares from a broker and sell them in the market in anticipation that the price will fall. They then buy the shares back at the lower price, returning them to the broker, and profiting on the price decline. The tactic can be used as a hedge against traditional investing or an aggressive play against a stock perceived to be overpriced, known as speculative short selling. In either case, the perception is that short sellers benefit from the misfortune of others. The U.S. Securities and Exchange Commission (SEC) imposed an emergency ban on short selling in September 11, 2008 soon after the fall of Lehmann brothers which caused the stocks to plummet. Similar restrictions came from Britain, Australia, Canada, Germany, Taiwan, Portugal and Ireland. When U.S. financial stocks fell on Monday September 15, experts said the shorts may have skirted the restrictions by using put options -- the option to sell a stock in the future at an agreed price -- or by shorting the entire index and buying the companies it did not expect to fall. The basic question remains unanswered here, "Does a ban on short selling have the desired effect?" "There is no academic evidence that short sellers by themselves brought a company down without other underlying reasons," said Paul Asquith, a profe ssor of finance at MIT's Sloan School who specializes in the study of short selling. This points out at the serious requirement of thorough studies on short selling and its effects. Hence my study exclusively focuses on the impact of short selling in the equity markets.

\subsubsection{The mechanics of short selling}

Despite its obvious importance to the operation of financial markets, the equity lending market is arcane. The market is dominated by loans negotiated over the phone between borrowers and lenders. Although there have been significant improvements in recent years, there is no widely used electronic quote or trade network in the equity lending market. An investor who wants to sell a stock short must first find a party willing to lend the shares. Once a lender has been located and the shares are sold short, exchange procedures generally require that the short-seller deliver shares to the buyer on the third day after the transaction $(t+3)$ and post an initial margin requirement at its brokerage firm. For instance in US, under Regulation T, the initial margin requirement is $50 \%$. Self-regulatory organizations (e.g., NYSE and NASD) require the short seller to maintain a margin of at least $30 \%$ of the market value of the short position as the market price fluctuates.

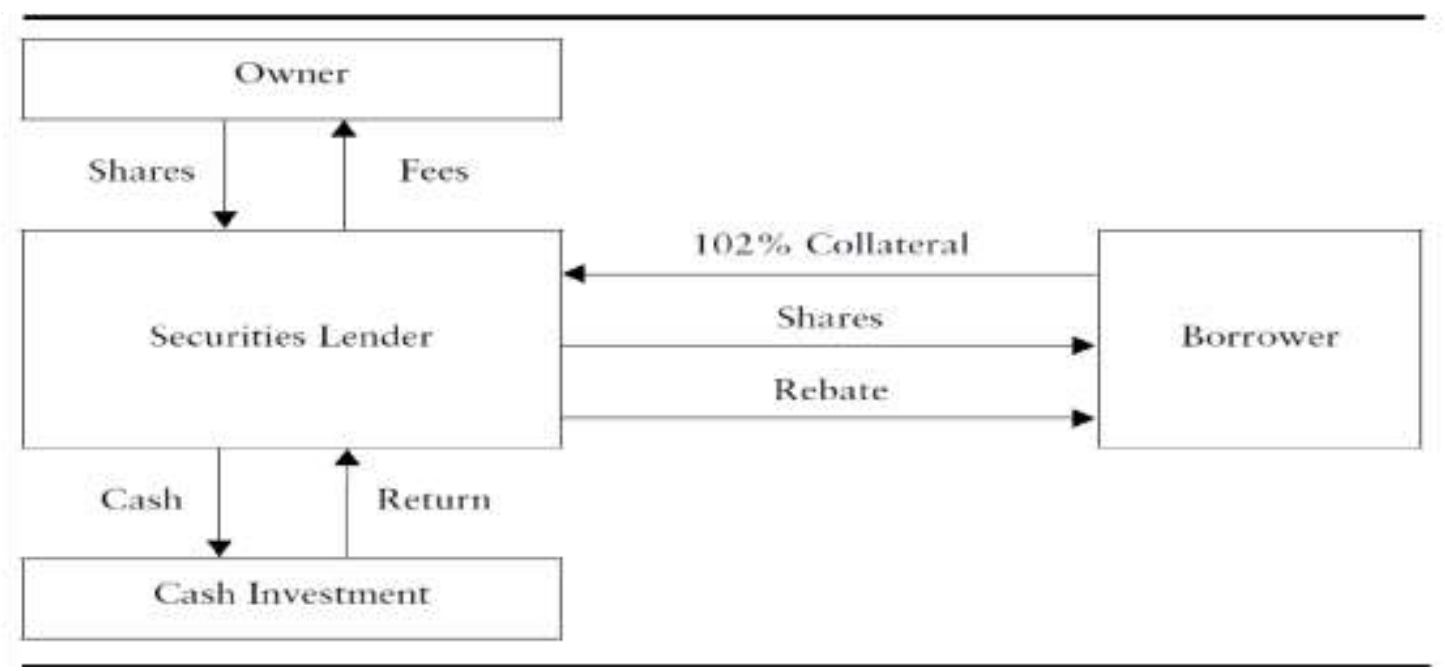




\section{Figure 1.1 Equity Loan Structure}

As described in figure 1.1, the proceeds from the short sale are deposited with the lender of the stock. For U.S. stocks, the lender requires $102 \%$ of the value of the loan in collateral. The value of the loan is marked to market daily; an increase in the stock price will result in the lender requiring additional collateral for the loan, and a decrease in the stock price will result in the lender returning some of the collateral to the borrower. When the borrower returns the shares to the lender, the collateral will be returned. While a stock is on loan, the lender invests the collateral and receives interest on this investment. Generally, the lender returns part of the interest to the borrower in the form of a negotiated rebate rate. Therefore, rather than fees, the primary cost to the borrower is the difference between the current market interest rate and the rebate rate the lender pays the borrower on the collateral. A lender's benefit from participating in this market is the ability to earn the spread between these rates. Although the earnings from this interest spread are often split between several parties participating in the lending process, the interest can add low risk return to a lender's portfolio.

\subsection{Statement of problem}

Though short selling is not considered as illegal there has been controversies and often strong demands for the restriction or the absolute ban of short selling. Short sellers are sometimes regarded with suspicion because, in the views of some people, they are profiting from the misfortune of others. Occasionally businesses campaign against short sellers who target them, even resulting in litigation. Advocates of short sellers say that the practice is an essential part of the price discovery mechanism. They state that short-seller scrutiny of companies' finances has led to the discovery of instances of fraud which were glossed over or ignored by investors who had held the companies' stock long. Some hedge funds and short sellers claimed that the accounting of Enron and Tyco was suspicious months before their respective financial scandals emerged.Such noted investors as Seth Klarman and Warren Buffett have said that short sellers help the market. Klarman argued that short sellers are a useful counterweight to the widespread bullishness on Wall Street, while Buffett believes that short sellers are useful in uncovering fraudulent accounting and other problems at companies. In response to the UK and US moves to ban short selling in September 18 and 19 of 2008, UBS stated: "This can be characterized as a populist reaction of no positive value. Anyone who seriously thinks that the cause of this crisis arises from the actions of evil and manipulative speculators lacks the insight and knowledge to be allowed anywhere near the regulation of financial markets. Short selling may well exacerbate problems, but it was not the cause."The biggest concern or critic is that short selling has often been associated with market abuse. Critics also have little time for pension funds and insurance companies that facilitate the process by lending out their shares. These large investors buy shares on behalf of their clients and presumably hope they will rise in value. So it seems bizarre that they're prepared to lend stock to people who want to make money from falling share prices.

\subsection{Research Objectives}

The impact of short selling on financial markets is a closely monitored topic especially with the recent controversies of temporary ban on short selling. The purpose of this research is to make a decisive conclusion of whether the ban of short selling improves the efficiency of the financial market. The specific objectives of the study are as follows:

- The role of short selling in the price discovery mechanism

- The effect of short selling in balancing the bullishness in the market

- The short sellers' ability to expose fraudulent and illegal accounting activities in the companies.

- The short selling impact on the falling stocks

- To find the loopholes in short selling which is adversely affecting the market

\subsection{Research Questions}

The research aims to find solutions for the following research questions. RQ1. Does the short selling play an inseparable role in the price discovery mechanism?

$\mathrm{RQ2.}$ What is the effect of short selling in balancing bullishness in the market?

RQ3. Does the temporary ban on short selling help the falling stocks to recover? RQ4. Does short selling cause sudden and excessive fluctuations of the prices of securities threatening fair and orderly markets?

$\mathrm{RQ5}$. Did the ban/restriction on short selling affect the volume of trading in the financial market?

RQ6. Do short sellers scrutiny of companies' finances help in exposing financial fraudulent? 


\subsection{Research Hypothesis}

Based on the above listed research questions, following research hypotheses are developed.

$\mathrm{RH} 1$. The short selling does play a major role in price discovery mechanism of different scripts

$\mathrm{RH}$ 2. Short selling is a key criterion which helps in balancing the bullishness of the financial markets and improves the market efficiency.

$\mathrm{RH}$. The temporary and partial ban on short selling does not help the market to recover at times of economic meltdown.

$\mathrm{RH} 4$. Since short selling is one of the few market forces in the complex financial market; short selling, acting as alone, does not cause excessive fluctuations of the prices of securities. effects.

$\mathrm{RH} 5$. Trading volume went up after the ban since more investors can trade freely without the fear of short selling

$\mathrm{RH} 6$. Short sellers scrutinise the financial statements of companies and can expose instances of financial fraudulent.

\subsection{Scope of study}

The research tries to probe into the depth and width of the short selling practices in the financial markets by primarily analysing the stock markets and commodity markets across the world with a focus on the main three stock exchanges a) New York stock exchange (NYSE) b) London Stock Exchange and c) Bombay stock exchange d) Chicago Board of trade (CBOT). The study will focus on adopting a global benchmarking strategy in dealing with the short selling practices. The study will also consider the other areas of short selling like in the commodity markets in establishing a conclusion of the impacts and effects of short selling.

\section{CHAPTER II: LITERATURE REVIEW}

\subsection{Introduction}

This chapter reviews the literature on the short selling on financial markets, the strategies and the risks involved with the art of short selling. Analogous to the cold war between the proponents and the opponents of short selling, the existing literature is also widely divided. Though there are divisive opinions and articles, a large majority of the articles do favour the existence of short selling. Despite the amount of opposing studies of short selling being comparatively low, there are strong opposition or pessimistic views among the investors, media and market participants about short selling.

\subsection{Introduction to Capital Markets and investing}

The basic reason for investment for any common man is to create wealth. When you just save the money without investment you are actually loosing money. Investment objectives must be stated in terms of both risk and return. Return objectives may be stated in absolute terms (dollar amounts) or percentages. Return considerations also cover capital preservation, capital appreciation, current income needs, and total returns. Specifying investment goals in terms of just return may expose an investor to inappropriate, high-risk investment strategies. Also, return-only objectives can lead to unacceptable behaviour on the part of investment managers, such as excessive trading to generate commissions (churning). Risk tolerance is a function of the investor's psychological makeup and personal factors such as age, family situation, existing wealth, insurance coverage, current cash reserves and income. The capital market is the market for securities, where companies and governments can raise long-term funds. It is a market in which money is lent for periods longer than a year. Otherwise, it is the market where debt or equity securities are traded. The capital market includes the stock market and the bond market. Financial regulators, such as the U.S. Securities and Exchange Commission (SEC), oversee the capital markets in their designated countries to ensure that investors are protected against fraud.

\subsection{Stock Market Functioning and Concepts in Trading}

Stock market is the market in which shares are issued and traded either through exchanges or over-the-counter markets. Also known as the equity market, it is one of the most vital areas of a market economy as it provides companies with access to capital and investors with a slice of ownership in the company and the potential of gains based on the company's future performance.

\subsubsection{Benefits of investing in shares}

Dividend income: investments in shares are attractive as much for the appreciation in the share prices as for the dividends their companies pay out.Easy liquidity: shares can also be made liquid anytime from anywhere and the gains can be realized in just two working days. Considering the high returns, the tax advantages and the highly liquid nature, shares are the best investment option to create wealth.

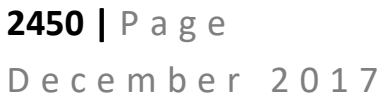

2450 | P a g e

D e c e m b e r 2017 w w w . cirworld. com

D $\mathrm{O}$ I : : 10.24297/jssr.v11i3.6470 


\subsubsection{Different ways investing in shares}

- $\quad$ Purchase shares from the primary market (IPOs)

The first time that a company's shares are issued to the public, it is by a process called the initial public offering (IPO). In an IPO the company offloads a certain percentage of its total shares to the public at a certain price. Most IPOs these days do not have a fixed offer price. Instead they follow a method called the book building process, where the offer price is placed in a band or a range with the highest and the lowest value (refer to the newspaper clipping on this page). The public can bid for the shares at any price in the band specified. Once the bids come in, the company evaluates all the bids and decides on an offer price in that range. After the offer price is fixed, the company either allots its shares to the people who had applied for its shares or returns them their money.

- $\quad$ Trade in the secondary market (stock exchanges)

Once the offer price is fixed and the shares are issued to the people, stock exchanges facilitate the trading of shares for the general public. Once a stock is listed on an exchange, people can start trading in its shares. In a stock exchange the existing shareholders sell their shares to anyone who is willing to buy them at a price agreeable to both parties. Individuals cannot buy or sell shares in a stock exchange directly; they have to execute their transactions through authorized members of the stock exchange who are also called stock brokers.

\subsection{Short Selling Debate}

Short selling is done by rogues, thieves, and especially pessimists, who are, of course, the worst of the lot. It is a terrible, terrible thing and must be stopped in our lifetime. We should halt it, restrict it, or at the very least revile those who make it their vocation. The above sentiments are sadly not imaginary or rare. Rather, they genuinely reflect much of the investing public's view of short selling. In fact, attacks have included proposals to make short selling harder (the existing "uptick rule" already makes it hard), or to make it impossible by banning it outright (presumably along with pessimism itself, and perhaps the infield fly rule). These criticisms and draconian proposals all increase in volume and seriousness when the stock market goes through a tough time. At such times many claim short sellers are the cause of the market's decline (Fabozzi 2004). Finally, at the low point for stock prices, many members of Congress invariably reexamine whether shorting should be allowed, or more simply, consider just legislating that the Dow go up 50 points a day.

Of course, the media does not help. A rising stock market is a good thing for ratings and circulation. This country is, of course, biased toward rooting for stocks to go up, and people watch and read more about this stuff when it is fun (i.e., going up). Thus, short sellers, with their gloomy attitude, are not generally media friendly. In fact, even some pro-free enterprise media outlets sometimes throw away their laissez faire stance when it comes to short selling, particularly "in times of crisis" (defined as an overvalued market getting a bit less overvalued). Apparently, they have some confusion regarding the difference between supporting a free capital market versus supporting an expensive one.

\subsection{Overview of short selling}

Selling a long position is the most obvious means of avoiding losses in what is perceived to be an overpriced asset. Short selling, on the other hand, offers a means not just to avoid losses but also to profit from knowledge of overpricing. Although the opportunity to short sell is not new, the surge in hedge funds, many of which used short selling to profit in the bear market, has focused renewed attention on the subject. In fact, many believe that the competition for alpha will force pension funds to relax the "no-short" constraint on their active managers (Bob Litterman, 2004). But for many investors, short selling remains an obscure, even mysterious subject, seemingly more akin to art than investment science.

Short sellers sell stock they do not own. The equity lending market exists to match these short sellers with owners of the stock willing to lend their shares for a fee. The equity lending market's importance is emphasized by its size: securities loans in the United States are estimated to be worth $\$ 700$ billion. Despite its obvious importance to the operation of financial markets, the equity lending market is arcane. The market is dominated by loans negotiated over the phone between borrowers and lenders. Although there have been significant improvements in recent years, there is no widely used electronic quote or trade network in the equity lending market. Short sellers see an overvalued stock that they assume will drop in price, so they borrow some shares from a brokerage firm and sell them immediately, at the stillinflated price. If the price drops, they buy back the shares and return them to the lender. If the price rises, the seller still buys them and ends up taking a loss. It's basically old fashioned trading, except in reverse. And because short sellers profit when the price falls, they are often blamed for driving a stock down. On Sept. 19, following one of the most turbulent weeks in stock markets' history, the Securities and Exchange Commission (SEC) banned short sales of 799 financial companies for just that reason. But defenders of short-selling say the practice doesn't cause a market to crash, it merely accelerates the fall. It's a little bit like ripping off a Band-Aid: you can do it the slow way or the fast way, but there's still going to be an injury underneath.

\subsubsection{Naked Short Selling VS Short Selling}

Naked short selling, or naked shorting, is the practice of selling a financial instrument short without first borrowing the security or ensuring that the security can be borrowed as is done in a conventional short sale. When the seller does not obtain the shares within the required time frame, the result is known as a "fail to deliver". The transaction generally
2451 | P a g e
w w w . cir w orld. com
Decem ber 2017
D O I : 10.24297/jssr.v11i3.6470 
remains open until the shares are acquired by the seller or the seller's broker, allowing the trade to be settled (Knepper 2004). The comparison of naked short selling and short selling is relevant in this study because quite often people get confused by the usage of both. Many refer naked short selling as short selling and vice versa. In this study, the whole efforts are focussed on short selling and naked short selling is not at all considered in any analysis. Hence it is really important to have a thorough understanding about naked short selling also to pursue a detailed research on short selling. In the United States, naked short selling is covered by various SEC regulations which prohibit the practice. In 2005, "Regulation SHO" was enacted; requiring that broker-dealers have grounds to believe that shares will be available for a given stock transaction, and requiring that delivery take place within a limited time period. As part of its response to the crisis in the North American markets in 2008, the SEC issued a temporary order restricting short-selling in the shares of 19 financial firms deemed systemically important, by reinforcing the penalties for failing to deliver the shares in time. Effective September 18, 2008, amid claims that aggressive short selling had played a role in the failure of financial giant Lehman Brothers; the SEC extended and expanded the rules to remove exceptions and to cover all companies.In naked short selling, the short sale occurs before the seller has actually borrowed the stock. If the seller can't borrow the shares in time, it's called a "failure to deliver" a practice that has been illegal since the SEC was founded in 1934, although investors have long found a way around the ban. Some failures are accidents; a computer glitch here, an unexpected difficulty there. But many are done on purpose, when the seller has no intention of following through with the deal. This does reduce a stock's price - all these people are selling, but no one is buying because there's not actually anything to buy - and has been illegal since the SEC was founded in 1934, although investors have long been able to find ways around the ban. If short selling is the sale of something you don't own, naked short selling is the sale of something that may not even exist. Victims of naked shorting can see thousands of phantom stocks trade hands every day, and there's not much they can do about it. Every time a market crashes, short selling is blamed because even legitimate short transactions - with stocks that actually exist - drive prices down faster. The London Stock Exchange banned short sales in 1787 to protect banking stocks after a large bank collapsed. After the 1929 crash, President Hoover publicly railed against short selling. New York State Attorney General Andrew Cuomo did the same thing last week, calling short sellers "looters after a hurricane." Then came the SEC's Sept. 19 ban, which pushed the Dow Jones Industrial Average up 370 points, even as market analysts called the move little but an ineffective and ill-advised band-aid. As short sellers would argue, they were merely pricking a bubble that was going to burst anyway.

\subsubsection{Academic Research on Short Selling}

There has been little academic research done on the impact of short selling on equity markets. A large majority of investors, security experts, government officials and other market participants have vindicated for major restrictions or the complete ban on short selling. The one major study, rather the only study made on the impact of short selling restrictions is the one done by Professor lan Marsh and Norman Niemer of Cass Business School, London, released by ISLA, AIMA and LIBA today in 2008 following the collapse of Lehmann Brothers and it's after effects on financial markets. Academics have questioned the wisdom of imposing short sales restrictions; primarily because of the effect such restrictions have on the efficiency of markets. Miller (1977), Diamond and Verrecchia (1987), Duffie, Garlenu and Pedersen (2002) and Bai, Cheung and Wang (2006) all present theories suggesting that prices may not fully reflect information when agents have heterogeneous beliefs but some are prevented from trading to express those beliefs. Miller (1977) suggests prices will be biased upwards in the presence of short sales constraints. Diamond and Verrecchia (1987) argue that prices will not be higher but that the speed of adjustment to new information is slower. Bai et al. (2006) argue that prices may actually be driven down by short sales constraints since the market knows that some information is not priced and hence demands a higher risk premium. While regular trading fills the market with people who only want their stocks to go up and will do anything to ensure that it happens - short selling creates people who want the market to go down, and therefore (its defenders say) does a better job at keeping the market honest. Short sellers were the first to discover problems at Enron, WorldCom and Bear Stearns. As Vanderbilt University economics professor Peter Rousseau puts it, "It's always good to have people on both sides." Critics, however, say that when short sellers pile into a particular stock, their borrowed 'sell' orders can swamp the market forcing the price to plummet. There is no academic evidence that short sellers by themselves brought a company down without other underlying reasons," said Paul Asquith, a professor of finance at MIT's Sloan School who specializes in the study of short selling. This points out at the serious requirement of thorough studies on short selling and its effects. After this statement was made a major study has been done exclusively on the restrictions of short selling by Professor lan Marsh and Norman Niemer of Cass Business School. Hence my study exclusively focuses on the impact of short selling in the equity markets. This includes from the examination of the impact of short selling in price discovery mechanism to the finding of a possible correlation between the stock exchanges which have banned short selling and the ones which have not banned short selling.

\subsubsection{Short Selling: Academic Theory versus Technical Analysis}

The academicians and market participants always differ in opinion regarding the restrictions of short selling. The difference does not end there. The perception or view point about the short interest is a classical example in this direction.Let us examine the details of the difference in the approach. Transactions data on short sales are not publicly available in the United States. However, the New York Stock Exchange (NYSE), American Stock Exchange (AMEX), and NASDAQ report short interest figures for individual stocks on a monthlybasis. The short interest in a stock is the aggregate number of shares that have been sold short and not yet covered. Whether these short interest figures contain valuable information about future performance has been a long-running controversy. Wall Street technicians, 
on the one hand, have traditionally viewed high short interest as a bullish technical indicator (Fabozzi 2004). On the other hand, most academic studies find that high short interest predicts negative future returns and therefore signals bearish sentiment. Trading is what impounds information into prices and competitive trading should result in an "efficient capital market." Even in a weak-form efficient market, by Fama's definition, it is not possible to reliably predict future performance from technical indicators or trading rules that are based on public market data. Fama recognizes, however, that traders will impound information into prices only to within the cost of attaining and trading on the information. It follows that the high cost of short selling, relative to regular sell or buy orders, constrains the trading necessary to fully impound bad news into security prices, and as a result some academic studies hypothesize that overpricing may exist in stocks that are costly to short sell.

Academic studies also suggest that the high costs of short selling imply that those who are willing to short sell, despite these costs, are likely to be trading based on superior information. In which case, increases in short interest may signal that informed traders have become more bearish about a stock; hence, the price should drop. On the other hand, the technician's view of short interest, as a bullish indicator, is based on the idea that short interest represents latent demand because short positions must eventually be covered by repurchasing the stock; thus, the price should increase in the future. Implicit in the technician's view is the risk of a so-called "short squeeze," in which prices move up very quickly as short sellers are forced to cover.

\subsection{Restrictions on short selling}

Traditionally, there has been a number of restrictions and ban on short selling. The restrictions on short selling are as old as the history of short selling. As much as $93 \%$ of the world's equity market capitalization is potentially shortable, there are particular regions of the world where it is difficult to take a short position (Fabozzi 2004). These include several countries in Southeast Asia and South America. When dual listings in markets allowing short sales are considered, the potentially shortable capitalization increases to $96 \%$. These numbers, however, mask important constraints to the global investor due to the inability to short particular sectors of the equity universe.

The restrictions on short selling has been on and off in different countries. Most exchanges vary the restriction based on changing market trends and situations. The Morgan Stanley Dean Witter Global Network Management Division (GNM) gave us a summary of information for 59 countries about short sales regulation and practice, compiled by their global network of subcustodian banks. The International Securities Lending Division at Goldman Sachs (ISL) gave us similar data. The ISL also contained information about the tax implications of securities lending and short sales for 46 countries (Fabozzi 2004). Both datasets indicated that there are several countries around the world in which shortselling is allowed. The figure 2.1 shows the statistics about the restrictions.

\begin{tabular}{|c|c|c|c|c|c|c|c|c|c|}
\hline \multirow[b]{2}{*}{ Year } & \multicolumn{3}{|c|}{ World Market Capitalizatien in Countries Where: } & \multicolumn{3}{|c|}{ World Market Capitalization } & \multicolumn{3}{|c|}{ World Market Capitalization (Excluting the U.S.) } \\
\hline & $\begin{array}{l}\text { Short Sales Are } \\
\text { Allowed and } \\
\text { Practiced }\end{array}$ & $\begin{array}{l}\text { Short Sales Are } \\
\text { Not Allowod } \\
\text { Not Practiced }\end{array}$ & Ratio & Shortable & Nonshortable & Ratio & Shortable & Nonshertable & Ratio \\
\hline 1990 & $\$ 81,163,692$ & $55,827,897$ & $93.30 \%$ & $581,553,36^{7}$ & $55,438,222$ & $93.75 \%$ & $\$ 56,865,489$ & $55,438,222$ & $91,27 \%$ \\
\hline 1991 & $\$ 85,274,817$ & 55,578 & $93.86 \%$ & & $\$ 5,137,639$ & $94.35 \%$ & $\$ 56,835$ & $\$ 5,137,639$ & $91,71 \%$ \\
\hline 1492 & $587,417,000$ & $\$ 6,781,783$ & $92.80 \%$ & $587,910,639$ & $56,298,144$ & $93,31 \%$ & $\$ 53,974,960$ & $\$ 6,298,144$ & $89,55 \%$ \\
\hline 1993 & $\$ 191,620,765$ & $58,627,665$ & $92.17 \%$ & $\$ 102,206,024$ & $58,042,406$ & $92.71 \%$ & $\$ 64,092,465$ & $58,042,4106$ & $88,84 \%$ \\
\hline 1994 & $\$ 117,619,058$ & $\$ 14,023,882$ & $89.35 \%$ & $\$ 119,007,014$ & $\$ 12,635,926$ & $90.40 \%$ & $578,746,862$ & $\$ 12,635,926$ & $86.17 \%$ \\
\hline 1995 & $\$ 129,496,520$ & $\$ 13,-32,840$ & $90,41 \%$ & $\$ 131,265,871$ & $\$ 11,963,489$ & $91.65 \%$ & $\$ 82,90,0, \$ 40$ & $\$ 11,96 i, 489$ & $87,40 \%$ \\
\hline 1996 & $5159,746,80^{\circ}$ & $\$ 12,226,042$ & $92.89 \%$ & $\$ 161,709,752$ & $\$ 10,263,09$ & $94.03 \%$ & $\$ 98,492,806$ & S1 $0,261,090^{-7}$ & $90,56 \%$ \\
\hline 1997 & $\$ 190,287,927$ & $\$ 14,968,125$ & $92.71 \%$ & $\$ 192,744,804$ & $\$ 12,511,248$ & $93.91 \%$ & $\$ 108,143,224$ & $\$ 12,511,248$ & $89.63 \%$ \\
\hline 1998 & $\$ 228,150,782$ & $\$ 14,201,662$ & $94.14 \%$ & $\$ 231,067,238$ & $\$ 11,285,206$ & $95.34 \%$ & $\$ 118,961,927$ & $\$ 11,285,206$ & $91.34 \%$ \\
\hline 1999 & $\$ 289,400,736$ & $\mathrm{S1}^{-}, 971,174$ & $94.15 \%$ & $\$ 294,573,81^{-}$ & $\$ 12,798,093$ & $95.84 \%$ & $\$ 148,475,055$ & $\$ 12,-98,093$ & $92.06 \%$ \\
\hline 2000 & $\$ 341,861,145$ & $\$ 23,188,439$ & $93.65 \%$ & $\$ 350,966,615$ & $\$ 14,083,469$ & $96.14 \%$ & $5180,748,296$ & $514,083,469$ & $92,77 \%$ \\
\hline 2001 & $\$ 286,069,825$ & $\$ 17,845,533$ & $94.13 \%$ & $\$ 292,645,485$ & 511264,873 & $96.29 \%$ & $\$ 145,440,441$ & $\$ 11,269,873$ & $42.81 \%$ \\
\hline $2 \times 12$ & $5246,785,645$ & $\$ 17,596,158$ & $93,34 \%$ & $\$ 252,772,035$ & $\$ 11,609,768$ & $95.61 \%$ & $\$ 125,930,823$ & $\$ 11,609,768$ & $91,56 \%$ \\
\hline
\end{tabular}

Fig 2.1 World Market capitalization and short sales restrictions.

\subsection{Conclusion}

The academic studies on short selling restrictions and its impact are comparatively less in number. The recent most published study is "The Impact of Short Sales Restrictions" by lan W. Marsh and Norman Niemer. This study is absolutely based on the stock returns. My study is deploying a different approach which a elaborate qualitative study which is well supported by the financial theory and the experience from the market participants. The big difference in
2453 | P a g e
w w w. cir world. c o m
Decem ber 2017
D O I : 10.24297/jssr.v11i3.6470 
this study is that it will consider the movement of indices and how quick the fall in stock indices during the financial meltdown of different markets which have different restrictions to the short selling. Though there are a large number of studies on short selling going on, most are still ongoing studies and a very few are published outside to be accessible. Since the findings will be hot in the market, most scientific findings are not yet completely disclosed or completely verified. My study will also hopefully give some insights about the debate on short selling.

\section{CHAPTER 3 RESEARCH METHODOLOGY}

\subsection{Introduction}

Chapter 3 discusses the strategies, procedures, processes and plans in the research methods adopted in the study. The chapter elaborates the design, collection, analysis and interpretation of the information gathered. Further this chapter covers the research questions, hypothesis, data collection and data analysis. The chapter explains the three sets of data used for cracking the six research questions.

The research studied the responses of the people who are associated with the investment banking which includes the investors, financial analysts, traders, financial professionals. This pool consists of professionals associated with Asia Pacific, US and the European markets. Their views on the prospects of the industry were analyzed. This chapter would help in analysis of the data collected from these sources. There are many constraints which are influential in the decision making process of research design, data collection and method of analysis. They may include budget, availability of data and time constraints. One of the biggest difficulties in the research was the availability of short selling volumes and this acted as a hurdle in the comprehensiveness of the research. The extent of the research can also be a small constraint as it may limit the in-depth analysis of the field due to the above mentioned barriers. The research data would be both qualitative and quantitative in nature.

The research methodology consists of three main components:

- Research Design

- Data Collection

- Method of Analysis

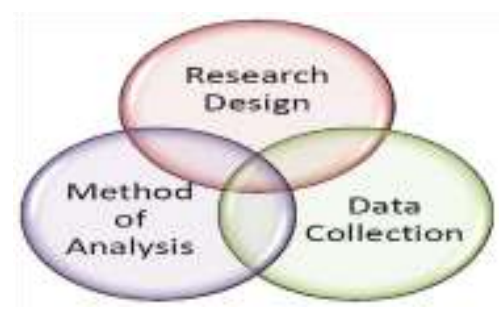

Fig:-3.1 Components of Research methodology

\subsection{Research Design}

Research Design is the general plan of how to crack the research questions. The research design would contain clear sets of goals and objectives that will be derived from the research questions. In addition to that it will also specify the sources from which the data would be collected and would also consider the constraints that will be encountered while collecting the data. The research is designed in such a way that the research questions are grouped into three sets. The RQ1 and RQ2 are grouped together and for analyzing these two RQs the data set of weekly closing price of crude oil is captured for 180 weeks till $3^{\text {rd }}$ week of May 2009. The RQs: RQ3, RQ4 and RQ5 are grouped together and for analyzing these, the data collected are of short selling restricted stocks from LSE. The last RQ6 is tackled by collecting primary data and for this a questionnaire has been sent across the financial professionals.

\subsubsection{Purpose of study}

The research questions can be answered in three ways, namely:

exploratory, descriptive or explanatory answers. The purpose of this study is to examine the facts in favor and against the criticism of the short selling. The major reason behind this is the restrictions and harsh criticism against the short sellers. To fulfill this purpose it is necessary to review the literature on short selling restricted markets and analyse the peculiarities the markets exhibit after the ban is made. Hence the purpose of the present study is descriptive and explanatory in nature. Descriptive study as it sounds, is a study that describes a phenomenon or event as it exists, without the manipulation or control of any of the elements involved in the event under study (Page \& Meyer, 2000). A descriptive study does not try and change anything about the research or the findings are not generalized, it is merely a description of what the research is about. In this particular study, with the analysis of the stock movements and the market forces in the financial markets the research hypothesis made are tested. The hypothesis made are either accepted or rejected. Moreover no alternative hypothesis is made. This analysis will expose some of the key
2454 | P a g e
w w w. cirworld. c o m
Decem ber 2017
D O I : 10.24297/jssr.v11i3.6470 
characteristics of the short selling which can be incorporated with the existing theories and insights can also be clubbed along with the other knowledge. Hence a comprehensive descriptive study will be used explain the research questions. Descriptive study helps to reveal the elements of the research and these elements can be integrated with other knowledge which can be used for exploratory study (Page \& Meyer, 2000). According to Miles and Huberman (1994) the purpose of explanatory researches is to clarify a phenomenon or make a complex issue understandable. It does so by clarifying the relationship between variables. This research has an explanatory purpose in that it aims to explain the key characteristics of the financial markets after the ban has been made.Another important aspect of the research methodology is the type of research approach. There are two types of research approaches namely, the deductive approach and inductive approach.

\subsubsection{The Deductive versus the Inductive Approach}

Marcoulides (1998) defines the deductive approach as a testing of theories. The researcher begins with a set of theories in mind and forms the hypotheses on their basis. After that, the research tests the hypotheses. The inductive approach, on the other hand, follows from the collected empirical data and forms concepts and theories on the basis of this data (Marcoulides, 1998).

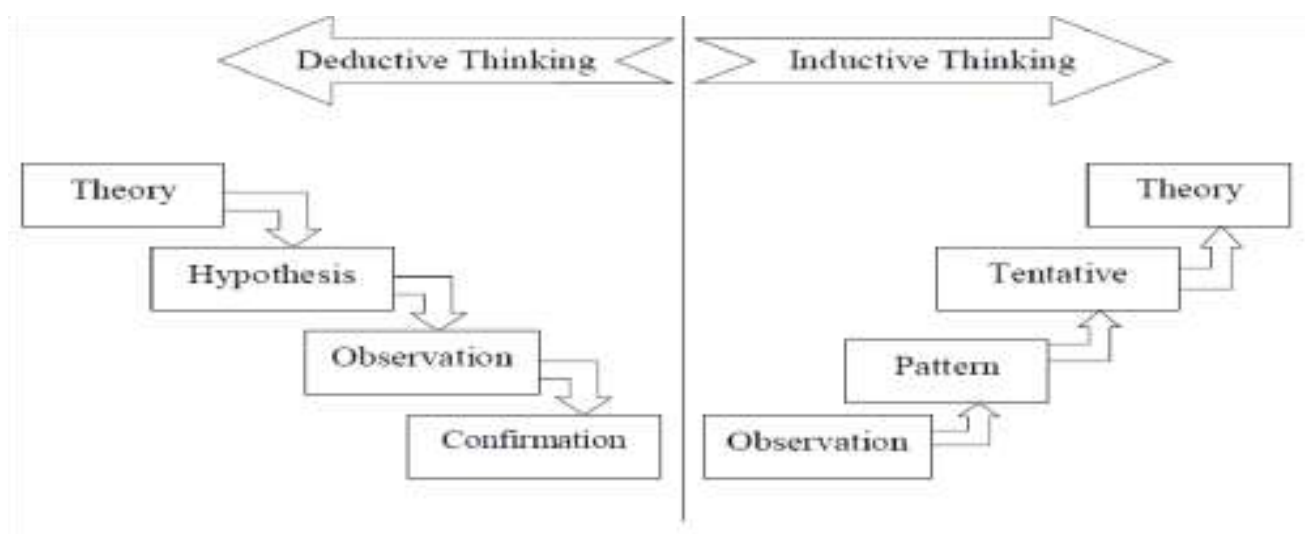

Source: adapted from Trochim (2001)

Fig:-3.2: Deductive Versus Inductive Approach

This study follows the deductive approach because it is beyond the expertise and the academic knowledge of the researcher to propose a theory and then test it through observation. Further, deductive approach was used where the hypotheses were developed and the research strategy was designed to test the hypotheses. A deductive approach starts with an idea or a conceptual framework and then uses the data to better understand and narrow that down into more specific hypothesis that can be tested (Hair et al., 2007). The reason for using this approach is that conclusions can be drawn from the available facts and evidences. Questionnaires in the form of surveys and secondary data would be used to collect information. The results would then be quantified and be presented in the form and charts and graphs. Based on these results the hypotheses would be rejected or accepted. Thus the deductive approach was ideal for this study.

\subsection{Data Collection}

Data collection is that part of the research process which is concerned with the collection of primary data. The data collection process consists of identifying the variables or phenomena, selecting the sample, selecting the type of data required, choosing appropriate collection methods, conducting pilot study, modifying collection methods and collecting the data (Hussey \& Hussey, 1997). Data collection involves procuring data from a sample of population and hence it is very important to explicitly define the sample, the sampling frame and the type of sampling method to be deployed.

\subsubsection{Secondary Data}

Secondary data is primarily collected through desk-based research. According to Jackson (1994) the value of a research is related to its data collection methods and importantly, whether or not it includes both secondary and primary data. As Creswell (2003) states, secondary data, which is an unobtrusive data collection method, depends on the location of pertinent and verifiable previously published academic studies and theories. After locating such data, the researcher should critically evaluate it in order to make sure that it is valid and reliable. This means that the researcher should only include in his study secondary data which is presented in academic researchers and articles which are verifiable and well-referenced (Creswell, 2003). Out of this consideration, the researcher of this study only used data which was obtained from electronic databases or libraries, articles or books and which was scholarly. Advantage of using secondary data is that it can be found quickly and easily especially when the requirements are geographically dispersed. Secondary data includes both raw data and published summaries. Data obtained from secondary sources can either be qualitative or quantitative in nature. Example of qualitative secondary data is the comments published in an article etc. Quantitative secondary data are bar charts, documents available on the internet, company websites etc

$\begin{array}{lr}2455 \text { I P a g e } & \text { w w w . c i rw or I d. c o m } \\ \text { D e c e m ber } 2017 & \text { D O I : 10.24297/jssr.v11i3.6470 }\end{array}$


(Cooper \& Schindler, 1998). The current study focuses on the stock market movements and hence it is important to collect the secondary form of data from reliable sources from newspapers, business journals and the internet such as the Yahoo finance, Bloomberg, the official websites of the stock exchanges and the stock brokerage firms. The nature of study is highly analytical in nature and hence the dependency on the secondary data is higher. It will be senseless to create primary data and analyses the whole short selling scenario based on the primary data alone. Nevertheless the usage of primary data is also vital since the human perceptions and emotions play an important role in determining the variations of the stock prices. The following discussion will further explain about the usage of primary data and means of collecting it.

\subsubsection{Primary Data}

Primary data includes the information collected by the researcher through systematic observations, surveys, interviews and questionnaires (Jankowicz, 2005). In primary data collection, you collect the data yourself using methods such as interviews and questionnaires. The key point here is that the data you collect is unique to you and your research and, until you publish, no one else has access to it. There are many methods of collecting primary data and the main methods include: Questionnaires, Interviews ,Focus group interviews ,Observation ,Case-studies .

In this study the use of questionnaires as a method of collecting primary data is deployed since it is easy and cheap to acquire such data. A questionnaire is a list of carefully structured questions which are chosen after considerable testing with a view to eliciting reliable responses from a chosen sample (Hussey and Hussey,1997). Questionnaires are a popular means of collecting data, but are difficult to design and often require many rewrites before an acceptable questionnaire is produced. Some of the main advantages of collecting primary data are as follows:

- $\quad$ Can be used as a method in its own right or as a basis for interviewing or a telephone survey.

- $\quad$ Can be posted, e-mailed or faxed.

- Can cover a large number of people or organisations.

- Wide geographic coverage.

- Relatively cheap.

Questionnaires can be of two types namely: closed end questionnaires and open end questionnaires. A closed end question is the one in which a question is asked and then a number of possible answers are provided for the respondent. The respondent selects the answer which is appropriate. Closed questions are particularly useful in obtaining factual information. Open ended questions are the ones where the participant would not be given options to select as an answer. The participants are expected to make a comment regarding the question asked. For the purpose of this study the participants were asked to mark their opinion about the ban on short selling. They have been given five choices. All the participants are from the investment banking which includes financial analyst, traders and other financial professionals. Most of them are well qualified and have expertise on this field. The qualifications of participants include graduate and undergraduate degree on finance, CFA, CFP, FRM etc. The questionnaires have been sent through different channels such as email and mails. The opinions of these professionals are really important since it can give different angle and insights into the study. Moreover the study can come out of the pure academic tag. Open ended questions are the ones where the participant would not be given options to select as an answer. The participants are expected to make a comment regarding the question asked.

\subsubsection{Population}

Population may refer to a body of people or to any other collection of items under consideration for research purposes. A sample is made up of some of the members of the population. Sample is a representative of the entire population and is reflective of the general opinions and perceptions of the population (Hussey \& Hussey, 1997). The population for this particular study is the group of all stocks listed in the stock exchanges across the world. However, for better accessibility this population can be restricted to the stock exchanges and the commodity exchanges in UK, US, India and China. Moreover, for the primary data collected the population is the list of all professionals associated with the stock exchanges.

Further, for the analysis of the first two research questions (RQ1 \& RQ2) the population is the set of oil prices in the last five years. The population for the next three research questions (RQ3, RQ4 \& RQ5) is the set of restricted stocks (stocks which are banned from short selling following the collapse of Lehmann Brothers) and the unrestricted stocks (stocks which are not restricted in the same period). For the last research question (RQ6) the population is the list of financial professionals associated with the above mentioned group. For this particular $R Q$ the questionnaire has been sent to 120 professionals, out of which 55 has replied. The reason for such a huge response is that, in the data collection some friends of mine who are associated with these markets helped in getting a prompt response. Many of those are direct acquaintance of my friends. 


\subsubsection{Sample}

A sample is a group of units selected from a larger group (the population). By studying the sample it is hoped to draw valid conclusions about the larger group. A sample is generally selected for study because the population is too large to study in its entirety. The sample should be representative of the general population. Sampling techniques provide a range of methods that enable you to reduce the amount of data you need to collect by considering data only from a sub-group rather than an entire population. There are two types of sampling techniques, probability and non-probability sampling (Saunders, Lewis \& Thornhill, 2000).

In this study the sample is the set of data collected from the different population as explained above. For the RQ1 and $\mathrm{RQ2}$, the population is the set of daily closing oil prices in the last five years. The sample is the set of weekly closing price of crude oil. Hence a stratified sampling technique is used. When sub-populations vary considerably, it is advantageous to sample each subpopulation (stratum) independently. Stratification is the process of grouping members of the population into relatively homogeneous subgroups before sampling. The strata should be mutually exclusive: every element in the population must be assigned to only one stratum. The strata should also be collectively exhaustive: no population element can be excluded. Further a systematic sampling is deployed and the weekly closing price is taken as sample for 180 weeks. The reason for selecting the weekly closing price is that, in the financial markets its often considered that one week can be a cycle in which the first day is the watchful day, the following three days are buying days and Friday is considered as the selling day. This is a logical assumption which is made out of the practical knowledge of the researcher and other professionals. For the RQ3, RQ4 and RQ5, the judgmental sampling technique is deployed. Judgmental sampling sometimes referred to as Purposive sampling, involves selecting participants in the sample for a specific purpose. In judgmental sampling the researcher's judgment would be used to select the sample participants. The researcher believes that the selected participants would represent the target population. The sample for these questions is the ones selected from the list of restricted stocks and unrestricted stocks.

\subsection{Method of Analysis}

The most important aspect of any research study is the analysis of the collected data. The success of the research depends on the ability of the researcher's analytical skills. To effectively convey the idea and knowledge acquired by the data collection it is important transfer this knowledge numerically and descriptively. Hence a combination of qualitative and quantitative methods would be used for analysis of the data. The quantitative tools for data analysis generally borrow from the physical sciences, in that they are structured in such a way so as to guarantee (as far as possible), objectivity, generalizability and reliability (Creswell, 2003). Here the researcher is objective and the research results are numerical. Qualitative tools, on the other hand, are based on content analysis, among other things and are presented in non-numerical format. Even though they allow the researcher to gain a very deep insight into the topic that he is investigating, they are not suited for all types of studies. In addition to that, the quantitative tools are objective and straightforward and, so, are ideal for testing the validity of certain hypotheses. The following figure will differentiate between the quantitative and the qualitative approach.
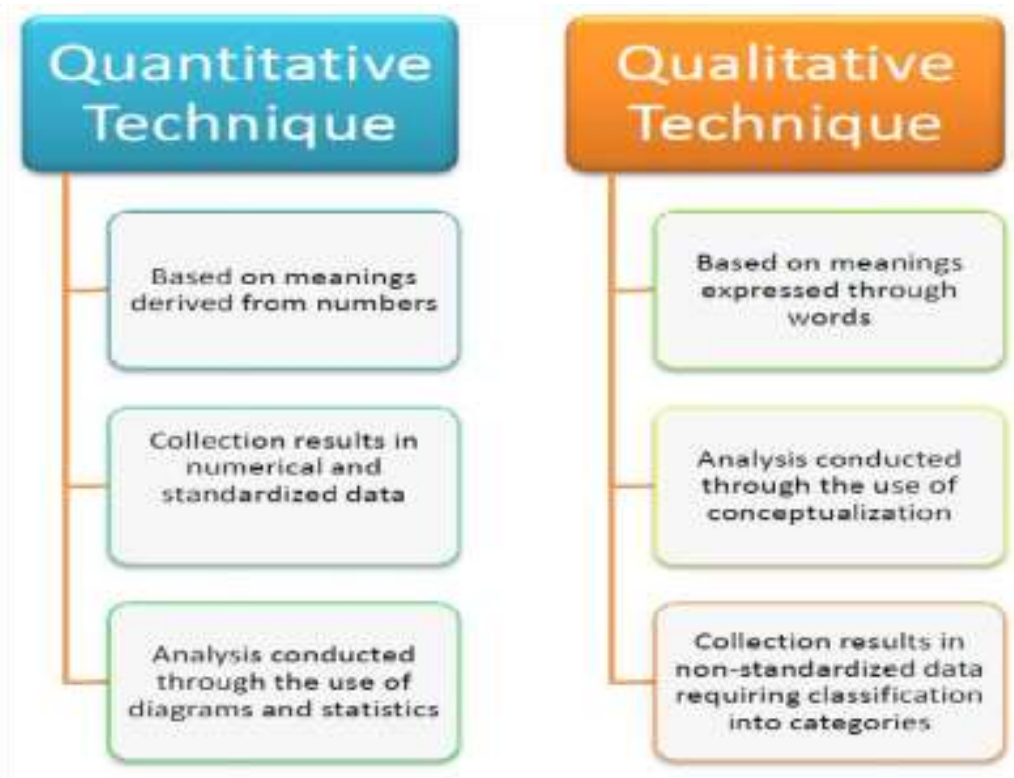

Fig:-3.3: Difference between Qualitative and Quantitative Techniques 
Quantitative data is primarily numerical in nature and based on these statistics various inferences and observations and be made out. For this study quantitative data is used extensively. Data from various databases, annual reports etc was collected. The analysis of the data is done using pie charts, histogram, bar charts, graphs etc. The data is analyzed used statistical software such as Minitab 15 and Microsoft excel. Since the study is extensively based on the numerical values existing in the financial markets most of the inferences and analysis is drawn out in a quantitative way. The explanations and descriptions are discussed based on the analysed data. Qualitative data used in the current study is mostly based on the questionnaire which has been sent to different professionals to understand the perception about the ban on the short selling. Though the questionnaires are closed end, the participants can also provide opinion about the same.

\subsection{Summary}

Based on the discussion provided in this chapter, the research methodology best suited for this study is quantitative with a deductive approach which uses both primary and secondary data. The next chapter will discuss in detail about the collected data, the inference made of that and finally the conclusion drawn out of the analysis.

\section{CHAPTER 4 - FINDINGS, INTERPRETATION AND DISCUSSION}

\subsection{Introduction}

In this chapter, the researcher discusses about the findings, interpretations and outcome of the study. This is chapter is classifies in such a manner that the findings on research questions are classified into three groups. The first two research questions are grouped together since the data collected for RQ1 can be used for arriving at a conclusion for the RQ2. The data collected is that of the weekly crude oil price for 180 consecutive weeks. For the first two questions the same data set is used for analysis. The research questions RQ3, RQ4 and RQ5 are grouped together and the analysis are made together using the same data set. The data set for this particular group is the stock prices of eight stocks in three phases from August 42008 to December 16 2008. For the final question RQ6, primary data is used which is collected by sending questionnaires to 120 people and out of which 55 responded. The findings and interpretation on each hypothesis is explained separately with adequate figures, tables, graphs and statistical figures.

\subsubsection{Findings on the first research question (RQ1 \& RQ2)}

The price discovery mechanism is the process in which the price of a commodity, script, stock or any valuable thing (say security) is valuated naturally by the different forces or practices in the financial markets. These forces/practices include supply-demand, arbitraging, speculation and short selling. Though the price of any commodity is primarily decided by the supply and demand, the heavily traded commodities like crude oil and gold are often decided by the financial practices in the markets which will make it into an efficient market. An efficient market always requires these inseparable elements such as arbitraging, speculation and short selling. Trading on financial markets is about obtaining prices. A good financial market is "an efficient market", where forecasts about future risk and return determine valuation. The price observed at an instant in time on the ideal efficient market is a good assessment of future risk and return. This price is not constant, because new information is being constantly generated in the economy. An efficient market must exhibit volatility (Ajay Shah 1998). When news breaks, prices must change. An efficient market is one where new information is rapidly captured into prices (a better market is one which reacts faster). This is often a market which appears to be highly volatile. A dollar-rupee exchange rate which does not move is the outcome from a market which lacks efficiency.

\subsubsection{Crude Oil- A perfect pick for research}

Crude oil is the world's most actively traded commodity, and the NYMEX Division light, sweet crude oil futures contract is the world's most liquid forum for crude oil trading, as well as the world's largest-volume futures contract trading on a physical commodity. Because of its excellent liquidity and price transparency, the contract is used as a principal international pricing benchmark. Additional risk management and trading opportunities are offered through options on the futures contract; calendar spread options; crack spread options on the pricing differential of heating oil futures and crude oil futures and gasoline futures and crude oil futures; and average price options.

In this study, the role of short selling played in the price discovery mechanism is evaluated by the price movements in the international crude oil. The reasons for selecting the crude oil as an indicator in the price discovery mechanism for this particular study are as follows:

1. Crude oil is one of the most traded commodities in the commodity market.

2. It is sensitive to the movements in the financial markets. The price variation is in line with the stock market movement across the world

3. It is the first indicator of price movements in the financial markets.

4. The crude oil supply has been constant and will remain mostly constant for a few more decades since the chances of exploring new oil deposits are bleak. 
The break even price of stocks is difficult to be calculated and hence to conclude the right price is very hard to be evaluated. It is practically impossible to judge the exact price of a stock. Here, the study tries to find out the break even price of the crude oil and analyse the price discovery and hence extrapolate that to the stocks, whereas it is not logical to do such an analysis straightway to the equity market.By analysing the impact of short selling in the crude oil industry, the analysis can be extrapolated to other market in concluding the price discovery mechanism of any script.

The following limitations and assumptions are also considered in the analysis of the crude oil price variation.

1. Crude oil is an ideal commodity in analysing the price discovery mechanism which is similar in characteristics to other natural resources like gold and silver.

2. The fluctuation of supply and demand is not very large; in other words the supply and demand is reasonably constant and the study will account for the supply cuts made by the producers.

3. The extrapolation of the conclusion made out of the crude oil study will reflect the same intensity in the other markets including equity markets.

4. The commodity market and the equity market have a similar functioning and behaviour. All the market characteristics of these two are comparable except the underlying nature.

\subsubsection{Discussion of Results}

In the study of the crude oil price variation a sample of 180 variants are taken. The weekly crude closing oil prices starting from $30^{\text {th }}$ December 2005 to $22^{\text {nd }}$ May 2009 are collected. This data is collected from the New York Stock Exchange website http://www.nyse.tv/crude-oil-price-history.htm. The population is the closing prices of crude oil in al the market functioning dates starting from $24^{\text {th }}$ December 2005 to $22^{\text {nd }}$ May 2009.

Further, the study analyses the break even price of crude oil price. The break-even price is the first thing oil companies establish in order to determine if drilling a new well makes financial sense (Austin 2008). From the break even price, profitability can easily be determined with the following formula:

Profitability $=($ Price of Oil - Break Even Price) / Break Even Price.

For example with oil at $\$ 100$ and a break even price of $\$ 50$, profitability is $100 \%$. But with oil at $\$ 60$ and the same break even price, profitability drops to $20 \%$. To have a clear understanding the break even price listed at the table 4.1 is further plotted to the profitability at $100 \$ /$ barrel which is furnished in the table 4.2.

The following table provided by the Bank of Kuwait gathered at the end of 2008 reported break-even prices of major oil producing nations:

\begin{tabular}{|c|c|}
\hline \multicolumn{2}{|c|}{ Oil Break-Even Prices } \\
\hline Nation & US\$/Barrel \\
\hline Bahrain & 40 \\
\hline Kuwait & 17 \\
\hline Saudi Arabia & 30 \\
\hline U.A.E. & 25 \\
\hline Oman & 40 \\
\hline Qatar & 30 \\
\hline Canada's oil sands & 33 \\
\hline
\end{tabular}

Table 4.1 Crude Oil break even prices

The table captures the approximate break even prices of crude oil in different oil producing nations. This indicates that the higher price is in Bahrain and the lowest is in Kuwait. Since most of the oil producing countries has strong business relations with the Bank of Kuwait, the break even prices are assumed to be the exact one based on which the oil companies operate. 


\begin{tabular}{|c|c|c|}
\hline Oman Prof & tability at $\$ 100 /$ barrel oil 40 & $150 \%$ \\
\hline Nation & $\begin{array}{l}\text { Break-Even } \\
\text { Price(US\$) }\end{array}$ & Profitability \\
\hline Kuwait & 17 & $488 \%$ \\
\hline U.A.E. & 25 & $300 \%$ \\
\hline Saudi Arabia & 30 & $233 \%$ \\
\hline Qatar & 30 & $233 \%$ \\
\hline Canada's oil sands & 33 & $203 \%$ \\
\hline Bahrain & 40 & $150 \%$ \\
\hline
\end{tabular}

Table 4.2 Profitability of crude oil @ \$100/Barrel

\subsubsection{Observation of captured Data}

The data set of the weekly crude oil price consists of 180 samples which has an average (mean) of $\$ 75.87$ standard deviation of 24.51 with a lowest value of $\$ 36.51$ and highest being $\$ 145.29$. Based on the data, a graphical summary (fig:-4.1) is plotted. We can see that most of the values fall in between the $\$ 60$ and $\$ 80$ mark. Out of the 180 samples collected 56 samples have a value above $\$ 80$.

\begin{tabular}{|l|l|l|l|l|l|l|}
\hline Mean & Mode & Median & Std Dev & Range & Min & Max \\
\hline 75.87 & 61 & 69.17 & 24.51 & 108.8 & 36.51 & 145.3 \\
\hline
\end{tabular}

Table 4.3 Statistical information of crude oil

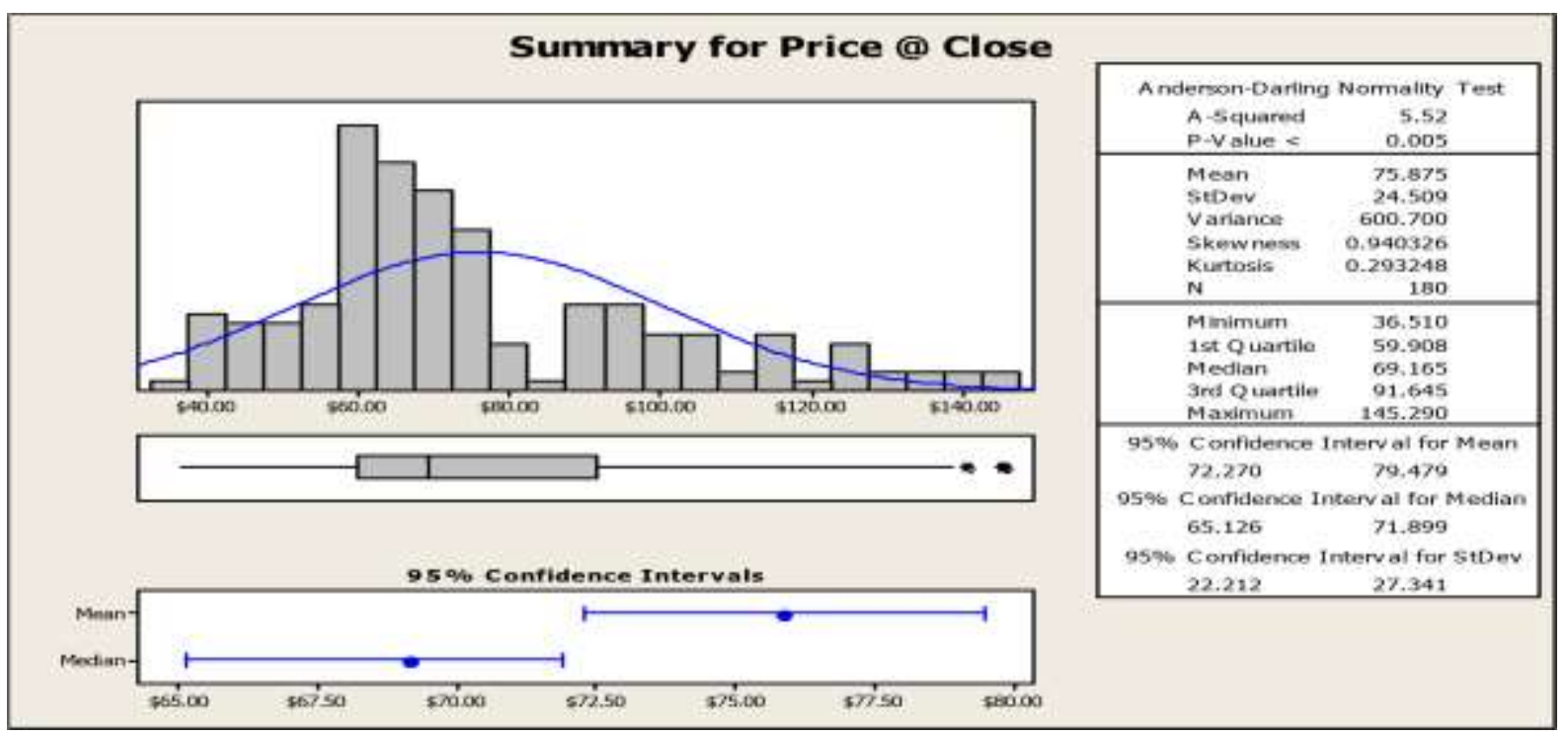

Fig:- 4.1 Histogram of Crude oil 
The mean value of the sample is $\$ 75.87$ which can be approximated to $\$ 76 /$ barrel. The profitability is calculated based on the formula:

Profitability $=($ Price of Oil - Break Even Price) $/$ Break Even Price

The profitability at the mean value is displayed in the table 4.4

\begin{tabular}{|c|c|c|}
\hline \multicolumn{2}{|c|}{ Profitability at \$76/barrel oil } \\
\hline Nation & US\$/Barrel & Profitability \\
\hline Bahrain & 40 & $90 \%$ \\
\hline Kuwait & 17 & $347 \%$ \\
\hline Saudi Arabia & 30 & $153 \%$ \\
\hline U.A.E. & 25 & $204 \%$ \\
\hline Oman & 40 & $90 \%$ \\
\hline Qatar & 30 & $153 \%$ \\
\hline Canada's oil sands & 33 & $130 \%$ \\
\hline
\end{tabular}

Table 4.4 Profitability at mean value

At $\$ 100 /$ barrel for crude oil the average profitability is a whopping $439 \%$ which is an overpriced situation or highly bullish by any standard, whereas at $\$ 76$ the average profitability is $167 \%$. Though, we may feel that the profit percentage is huge the main reason for this peculiar situation is that crude oil is a known stock of resource. Though the known stock is fixed at any point, it tends to increase over time as technological advances make more resources accessible. The rate at which this resource is supplied, also called "flow supply," is perfectly elastic at a price that equals the present value of the expected next-period price. To understand this concept, assume that the price of oil is expected to rise at a rate greater than the risk-free interest rate. Oil producing nations would curtail current production and produce more in the next period when the prices are expected to be higher. If the price of oil is expected to rise at a rate less than the risk-free interest rate, oil producing nations are better off increasing their current production and investing the proceeds to earn the risk-free rate of return. Based on this principle (the Hotelling Principle), the equilibrium price of oil is expected to rise at a rate equal to the risk-free rate of interest.

\subsubsection{THE OVERPRICING HYPOTHESIS}

Short sale constraints can prevent negative information or opinions from being expressed in stock prices, as initially discussed by Edward Miller in 1977. Although constraints are necessary in order for mispricing to occur, they are not sufficient. Constraints can explain why a rational investor fails to short the overpriced security, but not why anyone buys the overpriced security. To explain that, one needs investors who are willing to buy overpriced stocks. Thus two things, trading costs and some investors with downward sloping demand curves, are necessary for substantial mispricing. This willingness to hold overpriced stocks can be interpreted either as reflecting irrational optimism by some investors, or rational speculative behavior reflecting differences of opinion.

\subsubsection{Observation}

For further understanding, a time series graph of crude oil prices is plotted as shown in figure 4.2. Before the analysis, one important thing about the price discovery mechanism is that; in any commodity's price there are economic variants and financial variants. For instance, the primary economic variants are supply and demand whereas the financial variables can be the arbitraging, speculation, short selling etc. In strict arithmetic sense, the price is not just a function of these variables and the weightage of these factors are also important. The weightage of these factors are also different variables. Though it is comparatively easy to quantify the economic and financial variants, the prediction of exact price is difficult because of the role played by the weightage factors. It is nearly impossible to quantify the weightage factors which reflect the real market sentiments.

Mathematically, the price of a security (Ps) is a function of economic and financial variants. Though there are other factors which affect the price it is assumed that such factors are captured indirectly as financial variants.

$$
P s=F(w 1 E 1+w 2 E 2+w 3 E 3 \ldots \ldots \ldots \ldots+w n E n+w 1 F 1+w 2 F 2+w 3 F 3 \ldots \ldots \ldots+w n F n)
$$

The weightage of these factors are not equally distributed or neither is constant for any security at any given point of time. The major economic variants include the supply and demand whereas the main financial variants include speculation arbitraging and short selling. The short selling and speculation co-exist or rather they are two sides of a coin. 


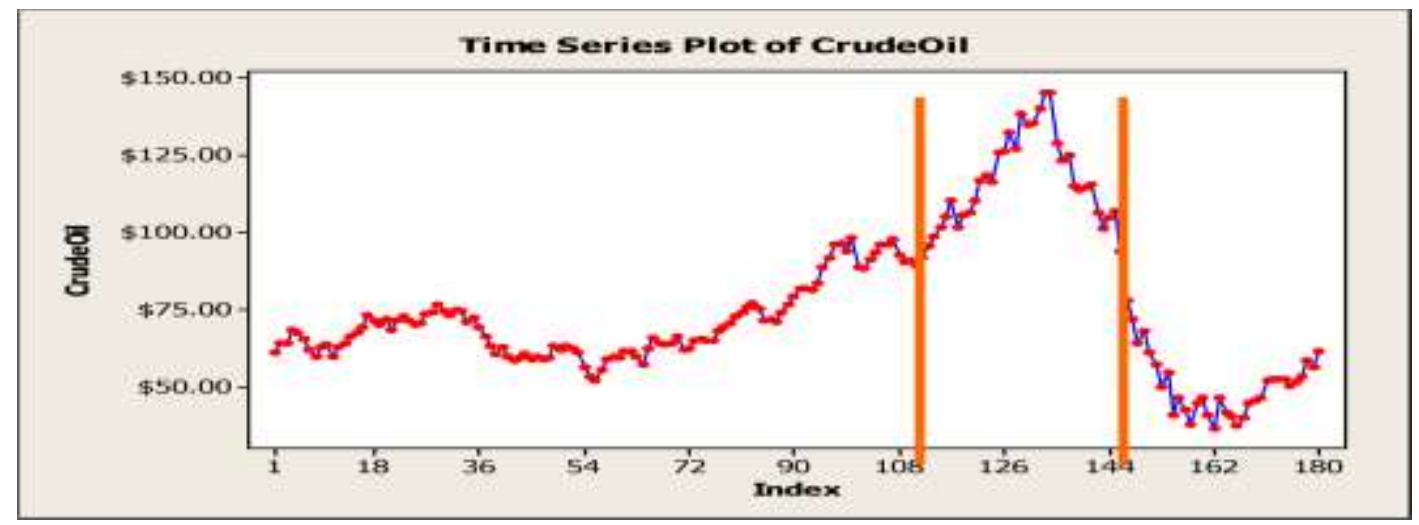

Fig 4.2 Time series graph of crude oil price

In the plotted time series graph we can see that there is an upward trend in the crude oil price, which is considered normal because most of the securities have inflationary growth. In the portion between the vertical lines there is a steep upward trend which is between the period; the week number 110 and the 142 . This period is an extraordinary upward tending time in terms of the growth of the crude oil price and it is much above the risk-free rate of interest. Suppose an investor is interested to take position in the crude oil commodity at the start of the week 110 . The primary thing he will review is to go long or short. Since the price of crude oil had broken the records the important question is what has driven the crude oil price to such a high level. Is there any higher rate of consumption of petroleum products which has driven the price? Or is it due to the increase demand of investors in the commodity market which made a rally in the crude oil price?

We can infer from the profitability table shown earlier that the reason for the crude oil price movement was mainly due to the high demand among the investors. Also, during this period there was no situation across the world which has caused increased usage of petroleum products proportional to the price movement. Hence it should be inferred that the price movement was primarily due to increased investors' participation. So, an investor at this position will conclude that it is an overpriced situation and the probability of him going for short position is higher. This is what happens at each stage. We can see that there is an overall trend of upward price movement even before the week 110 . Also, during this period atleast once in every three weeks, there is a fall in price. This is the balancing action of short selling. The critical- minded investors will go for a short position when he feels that the price has exceeded much higher than the value it actually possess. So at each stage there is a tentative downward pull by the short selling participants. This eventually nullifies or neutralise to an extent the hyper-bullish position in the market. Similarly, this nature is true for the capital markets also. It should be also noted that the steep decline in crude oil price from week number 134 to 160 is not necessarily due to the short selling effect. It is the selling pressure which had triggered the negative rally. During this period the sub prime crisis hit the peak and led to the fall of Lehmann Brothers and the investment banking. Hence it is the cumulative effect of so many factors which led to the slide in price and it will be illogical to conclude that the short selling drives the price down from a peak to rock bottom. The significant inference from this study is that the short selling helps in driving a price down to the probable actual price of an overpriced script at each stage. Here also, it exerts some downward pull but not strong enough to pull $70 \%$ of a script value. So it is true to infer that in the price discovery or in attaining the true price of a commodity or a script short selling plays a crucial role. While attaining so, it also balances the hyperbullish position in the market. be accepted.

Based on the explanations and justifications given above the research hypothesises $\mathrm{RH} 1$ and $\mathrm{RH} 2$ can

\subsubsection{Findings on the research questions (RQ3, RQ4 \& RQ5)}

For the analysis of these three $\mathrm{RQs}$ the data is collected from Yahoo finance. A total of 96 days' stock values of 8 stocks are collected. The classification of data and findings on each questions are explained below.

\subsubsection{Strategy and Selection of stocks for analysis}

In this particular analysis, UK is selected as a reference country for since it is the first country which has introduced ban on short selling after the fall of Lehmann Brothers and the countries follow the same channel afterwards. As mentioned in the literature review, the only major academic research on the ban of short selling, "The Impact of Short Sales Restrictions" by lan W. Marsh and Norman Niemer in Cass Business School, London acts as a guide in the further study. To understand further, we use stock return data of 8 companies over the period 4 August 2008 to 16 December 2008 in the analysis. The data (i.e. including dividend payments) of selected number of restricted stocks in UK are downloaded from Yahoo Finance. In the UK, for example, we use the FTSE 350 - the 350 largest UK listed stocks. From the Cass study, we can see that the stocks subject to the restrictions (hereafter "restricted" stocks) and those not affected by the restrictions ("unrestricted" stocks). For convenience and uniformity, the current study will also use the same nomenclature. Different from the Cass study, we split the full sample into 3 sub samples: 
The period after restrictions were introduced, i.e the ban period (19 September to 31 October 2008 for the UK, for example), and the immediate prerestrictions period

(hereafter pre-ban period) (4 August to18 September 2008), and a post restriction period (1 November 2008 to December 16), which be the post-ban period here onwards. In other words, the period selected is 135 days out of which the ban period is 43 days and the pre ban period is of 45 days and the post ban period is of 45 days. The Cass study has identified 34 restricted stocks out of which they have selected 23 stocks which are traded. For better convenience, we select 7 financial stocks out of the 23 stocks available for this particular study. The stocks selected for this particular study are as follows:-

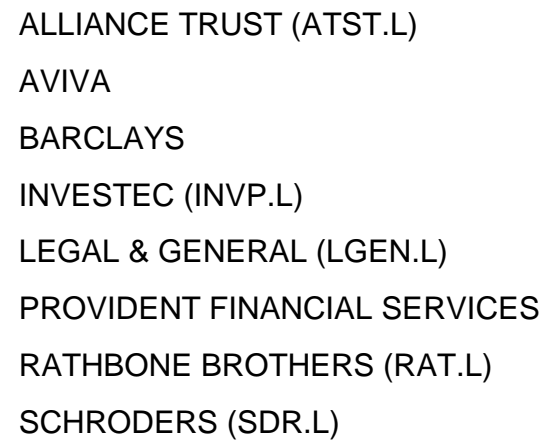

\subsubsection{Analysis of data}

The data for this particular analysis is collected from Yahoo finance and it should be noted that the stock values are represented in Pennies and not in Pounds. The graphical summary of each set of data is made. In the analysis, the mean, standard deviation, variance, skewness and kurtosis of the stock values are calculated. The Anderson-Darling test is conducted to estimate the normality test; in otherwords each set of data is tested to check the normality with a confidence level of $95 \%$. In addition to this the data is segmented into four quartiles also in order to understand the spread of the data. In this analysis the sample size in the post ban period is 32 , that in the ban period is 31 and that of the post ban period is 33 days. We have selected the period of 135 days out of which 96 days are the business days. Hence we have a total group of 24 such data set of 8 stocks in 3 periods. The strategy or logic behind the classification of data in such a manner is that, the three groups of data represent three phases in the capital markets. The pre ban period is the time when the stocks started sliding down following the collapse of investment banking in United States and its tremor. This period is the immediate preceding period of the short selling ban. The ban period is the time when short selling is banned or to be precise the restricted time. The post ban period is the period after the short selling restrictions are lifted. The stocks thus grouped are analysed and a graphical summary is made. Once the graphs are obtained, the comparison of three phases is made.

It should be kept in mind that the same stocks had almost equivocal stress and pressure from the market forces. The market forces are almost exerting the same pressure across this period except the change in the short selling restrictions. The key differentiating market force in these three phases is the short selling. It should be noted that the market was under pressure following the subprime crisis in the pre-ban period also. Hence it will not have any serious fallacy in the comparison of the three phases analysed. Nevertheless, the study also respects the fact that no two periods in capital are congruent in nature. The argument behind the comparison is that there were not any major changes in economic policies or extreme calamity or terrorist attack during these periods which would imbalance the study. The situation was adverse only due to the market behaviour and not due to any external forces.

\subsubsection{Discussion of results}

There are 24 sets of data collected of eight stocks on three different periods. The collected data is then processed using the statistical software Minitab 15. The figures 4.3, 4.4 and 4.5 give the statistical summary of Alliance trust. We can see that the mean and the standard deviation in the pre ban period are 309.31 and 10.49 respectively; in the ban period they are 260.11 and 27.90 respectively and 249.92 and

11.42 in the post ban period. There is a downslide in the stock prices in this period. Similarly most of the outcome has given a wide range of insights in understanding the problem. The graphical summary represented in the figures 4.3 to 4.26 shows the statistical variations. Each of the outcomes of the test is discussed separately.

\subsection{Anderson-Darling Normality Test}

The Anderson-Darling test is used to test the distributional adequacy of a sample data from a population. In this analysis, the Anderson Darling test is used to test the normality of the sample data. If the P-value is greater than 0.05 then the sample follows a normal distribution curve for $95 \%$ confidence level.

The key observation regarding the Anderson-Darling test conducted on the 24 sets is that most of the sets follow a normal distribution curve. The follow curves do not follow the normal distribution:-

2463 | P a g e

Decem ber 2017 w w w. cirworld. com

D O I : 10.24297/jssr.v11i3.6470 
1. ATST.L- Pre Ban period

2. Barclays- ban

3. Legal \& General-Ban

4. Rathbone Brothers- Ban

5. Rathbone Brothers- Post ban

Except the data set of the Rathbone brothers, the data sets tend to be normally distributed. Hence in the normality test inference we have to ignore the pattern of this particular stock. We can see that the normal distribution pattern is disturbed during the ban period for Barclays and Legal \& General. Otherwise all the other 19 sets follow a normal distribution pattern.

Hence the statistical inference from this data analysis is that most of the stock price variations of restricted stocks tend to follow normal distribution curve irrespective of the ban.

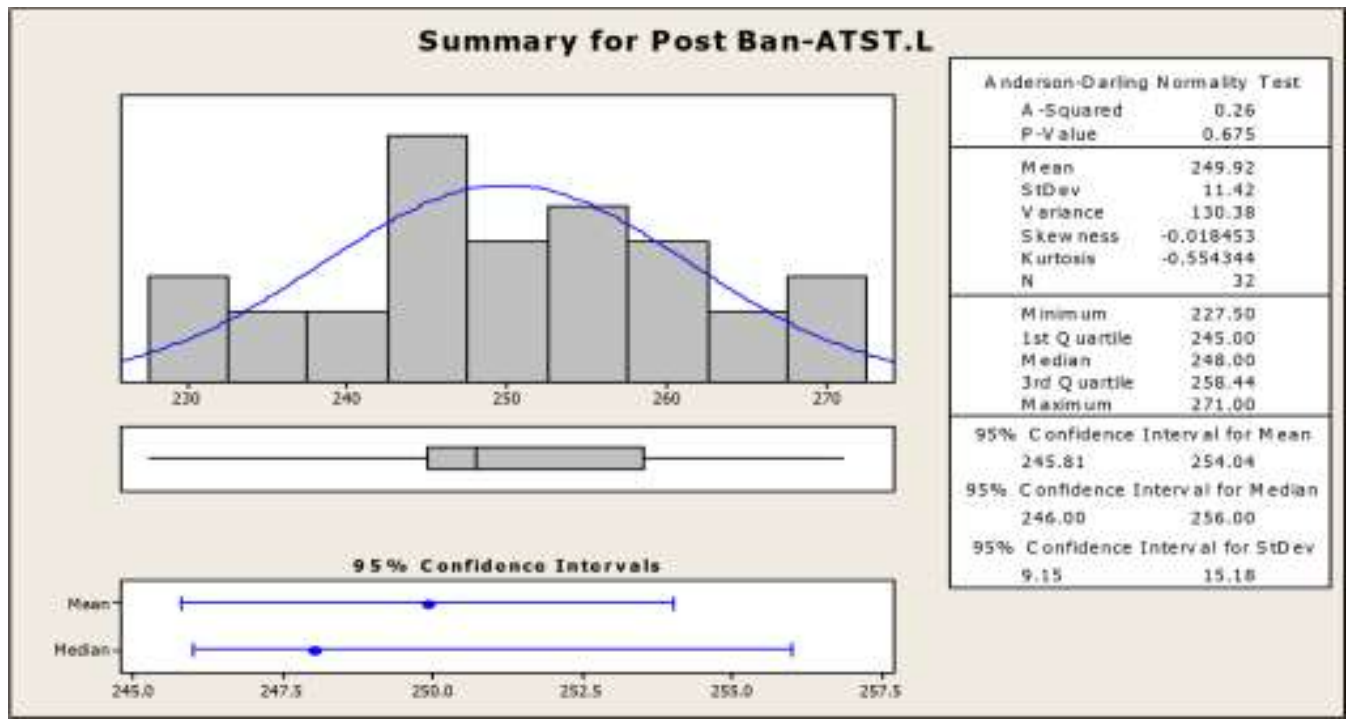

Fig:- 4.3 Summary of Post Ban for Alliance Trust

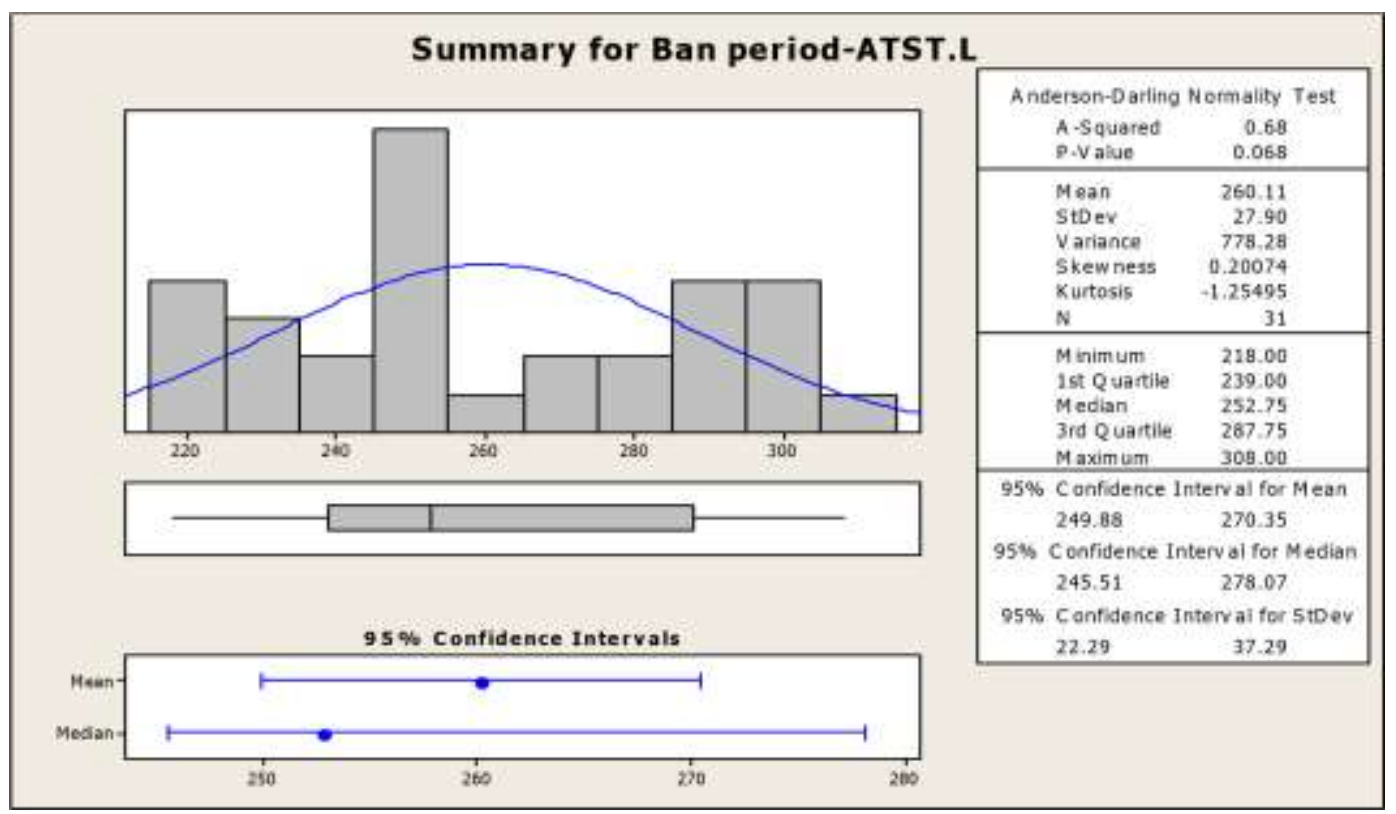

Fig:- 4.4 Summary of Ban period for Alliance Trust 


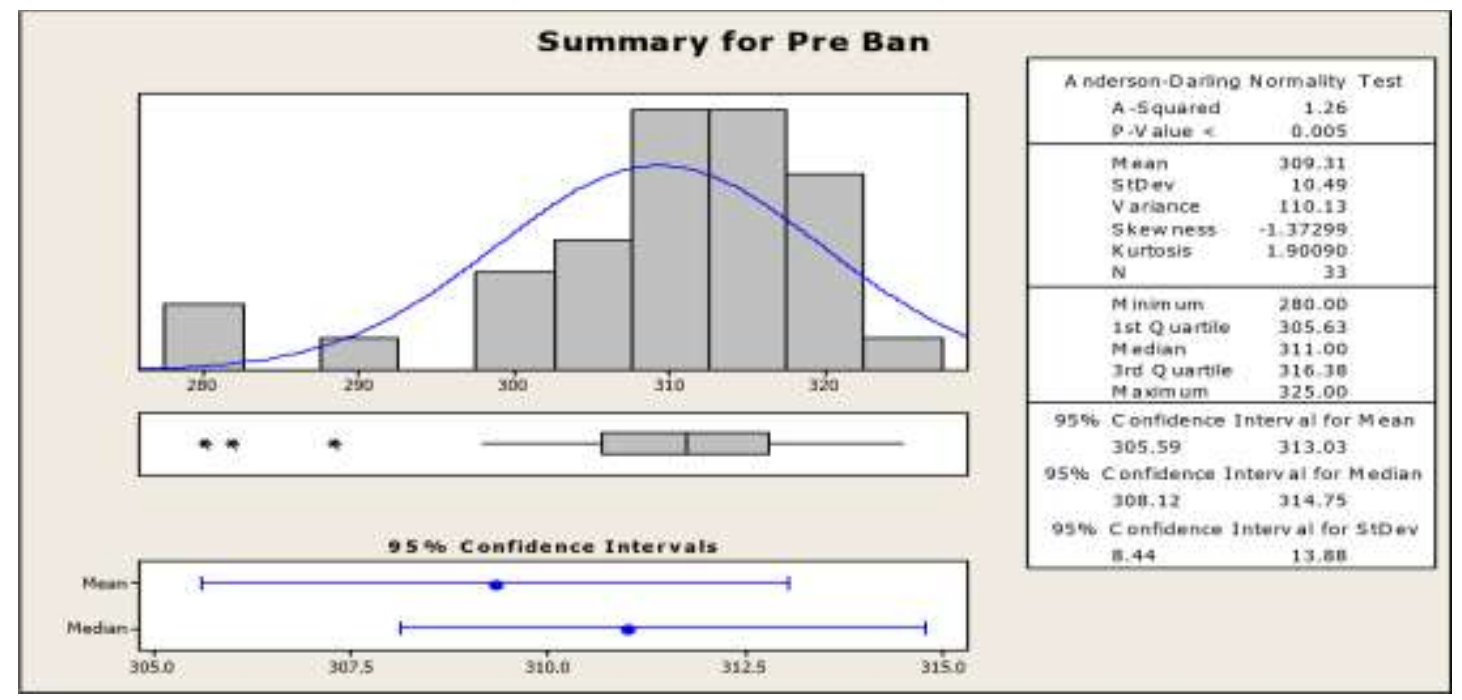

Fig:- 4.5 Summary of Post Ban for Alliance Trust

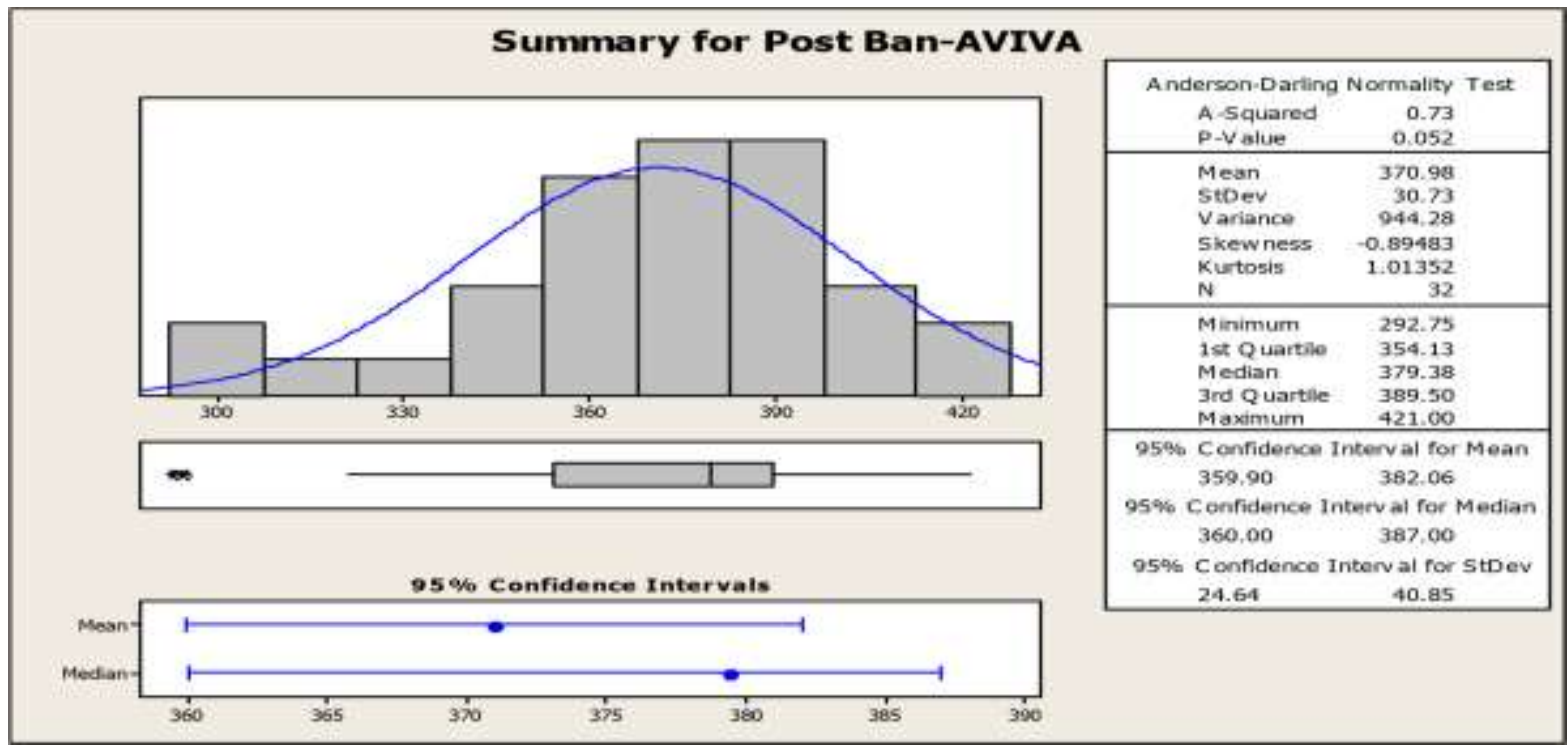

Fig:- 4.6 Summary of Post Ban - AVIVA

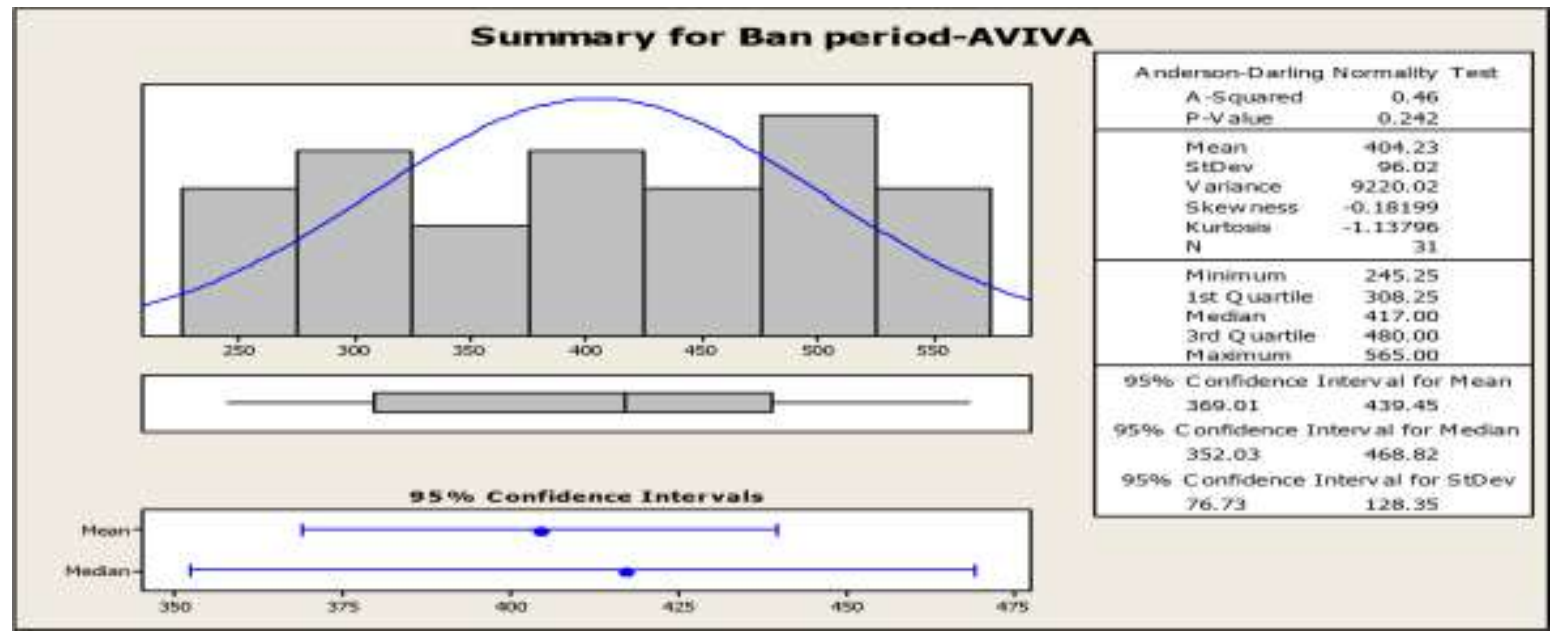

Fig:- 4.7 Summary of Ban Period - AVIVA

2465 | P a g e

w w w. cirworld. co m

De ce m ber 2017

D O I : 10.24297/jssr.v11i3.6470 


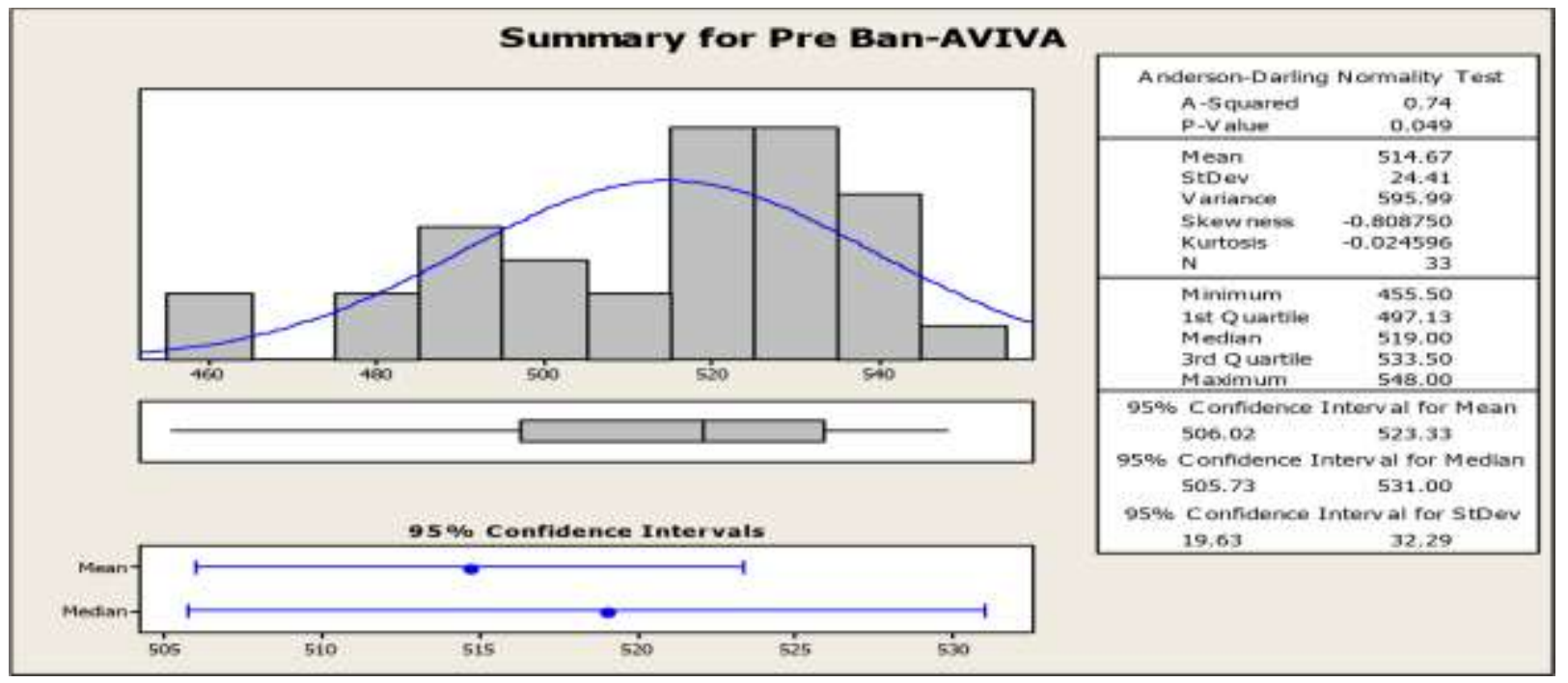

Fig:- 4.8 Summary of Pre Ban - AVIVA

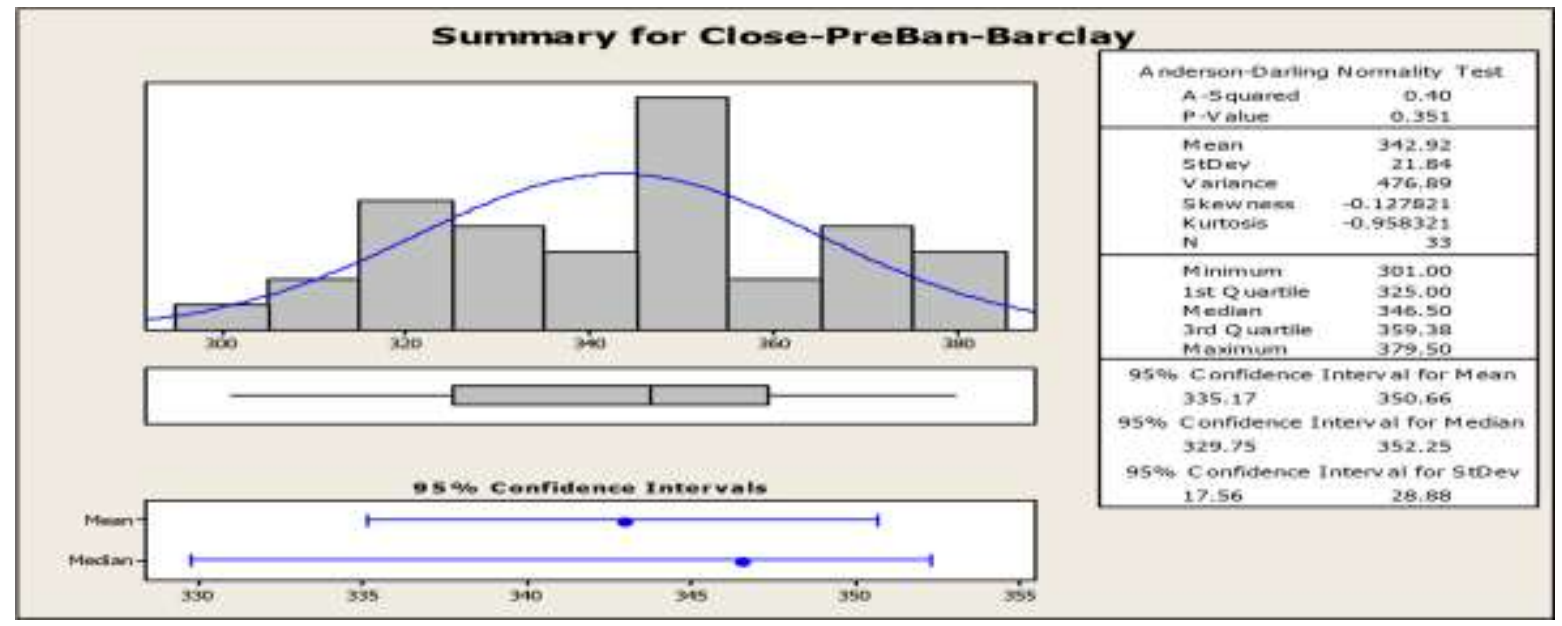

Fig:- 4.9 Summary of Pre Ban - Barclays

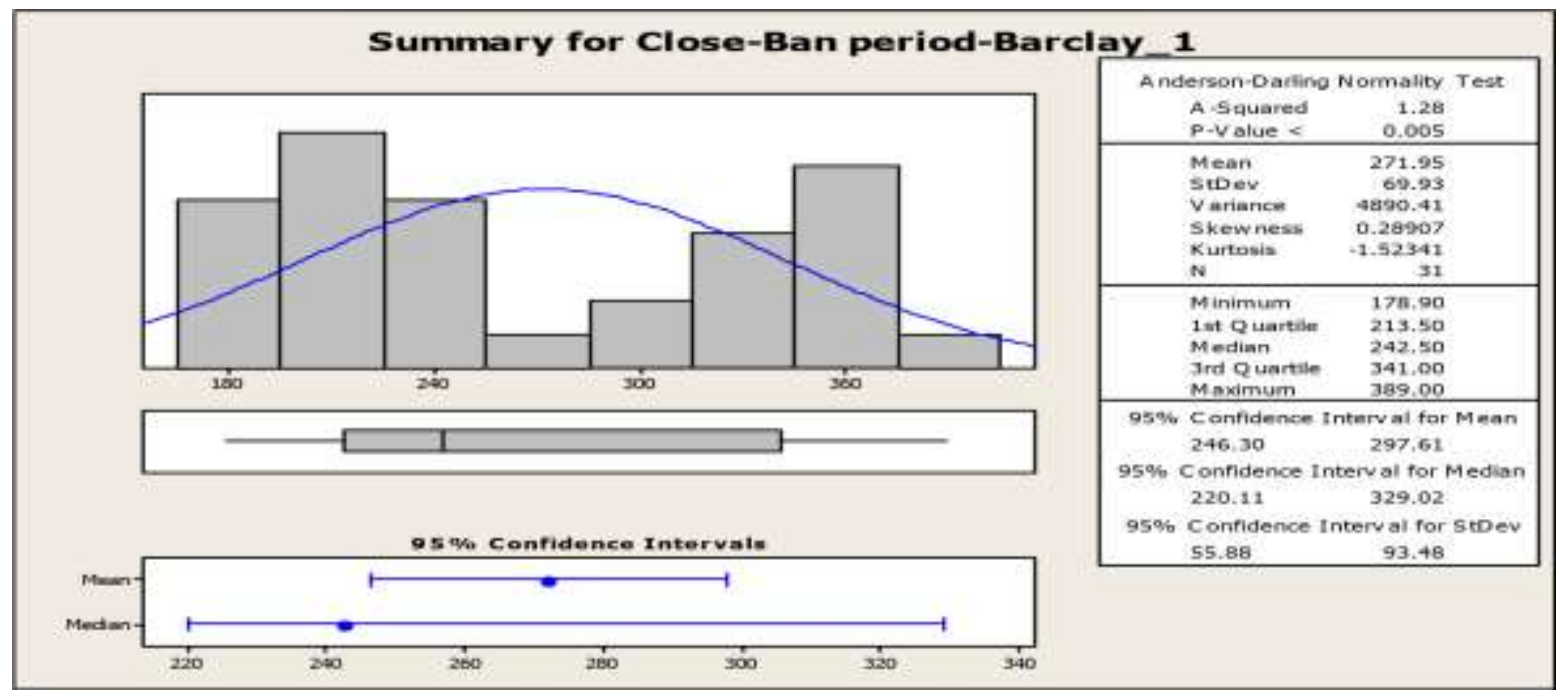

Fig:- 4.10 Summary of Ban period - Barclays

2466 | P a g e

w w w. ci r w orld. c o m

December 2017

D O I : 10.24297/jssr.v11i3.6470 


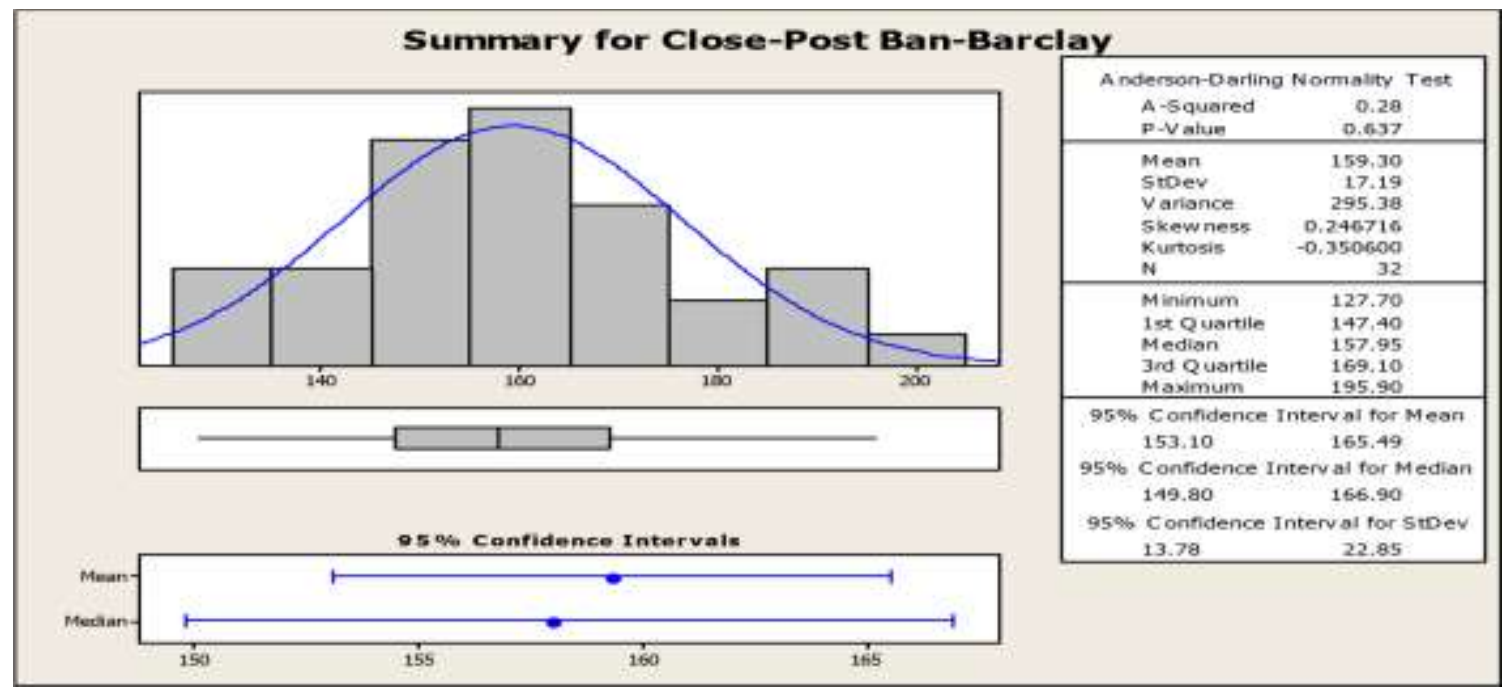

Fig:- 4.11 Summary of Post Ban - Barclays

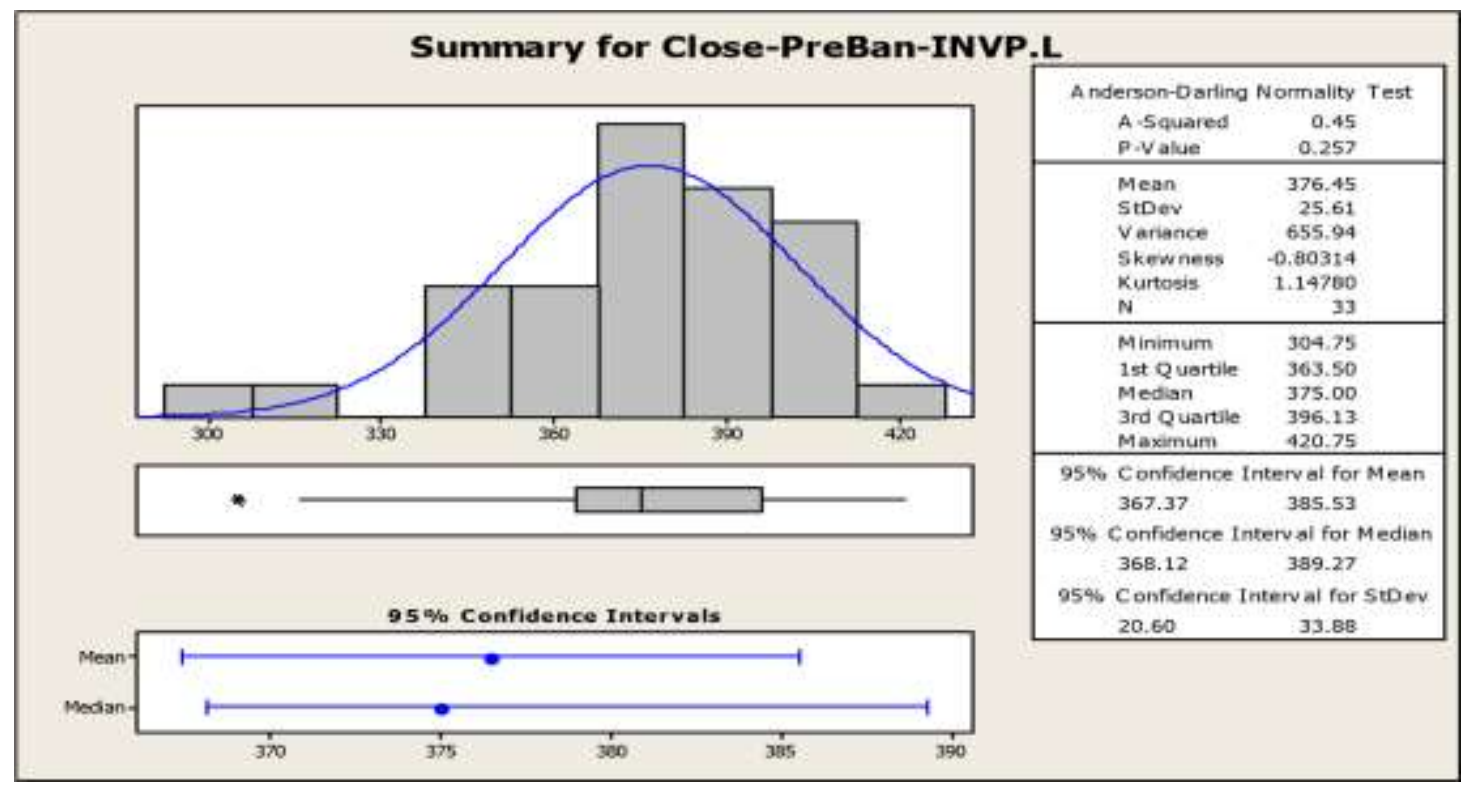

Fig:- 4.12 Summary of Pre Ban - Investec

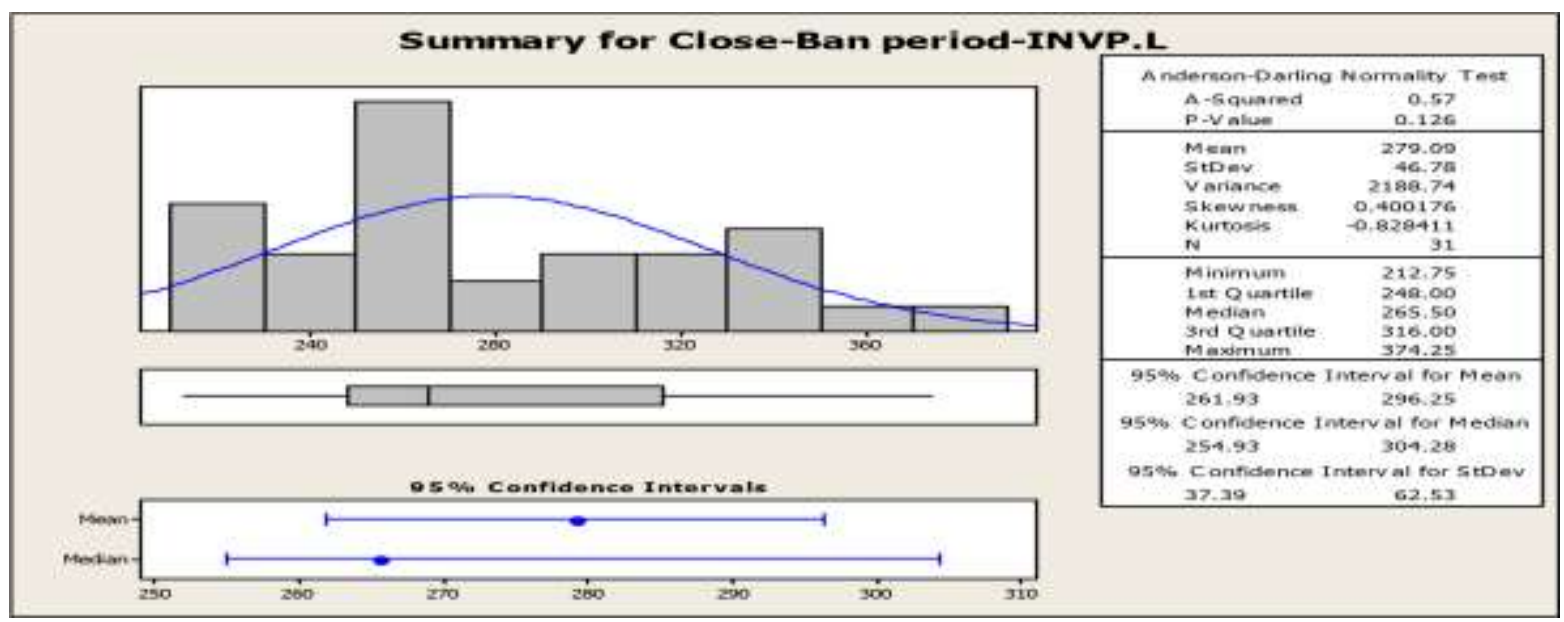

Fig:- 4.13 Summary of Ban period - Investec

2467 | P a g e

w w w. cirworld.com

December 2017

D O I : 10.24297/jssr.v11i3.6470 


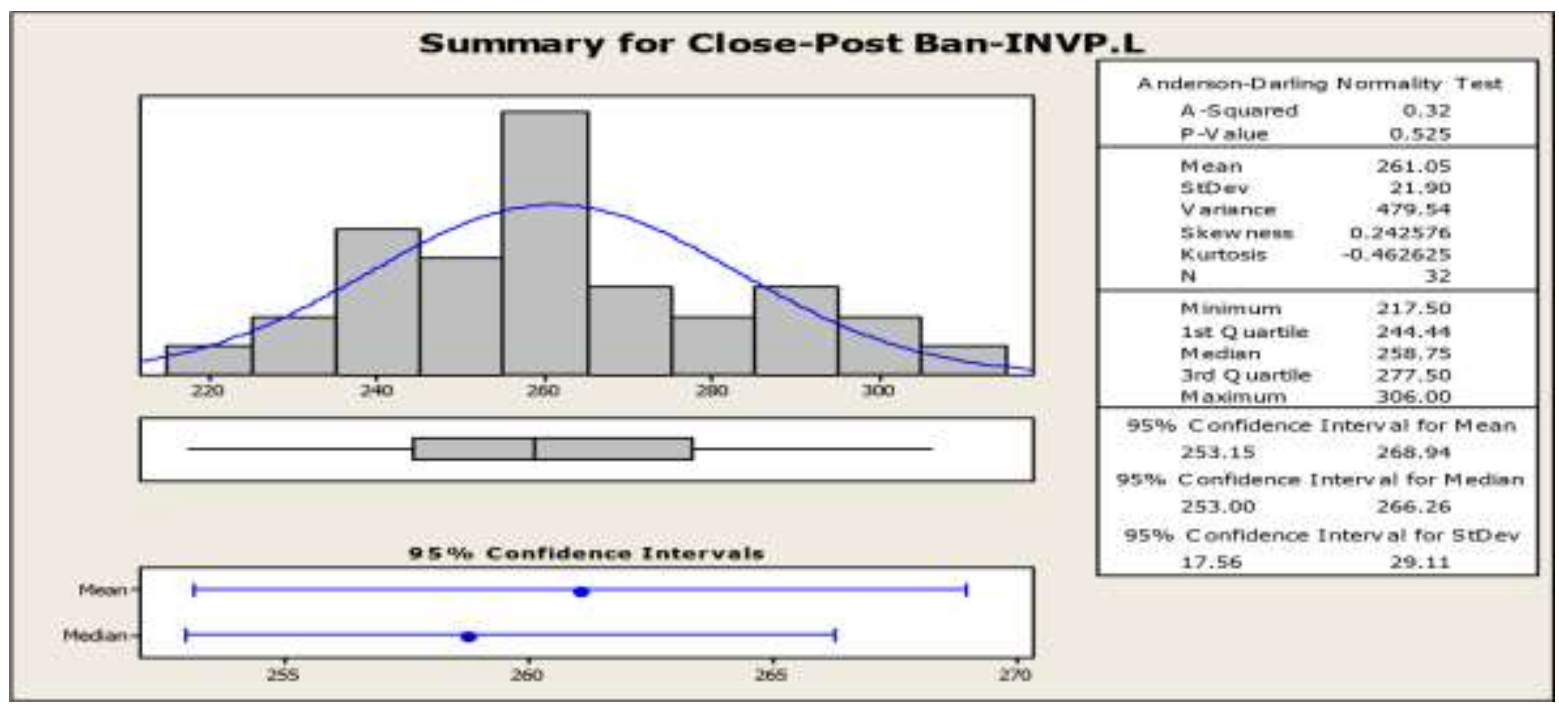

Fig:- 4.14 Summary of Post Ban - Investec

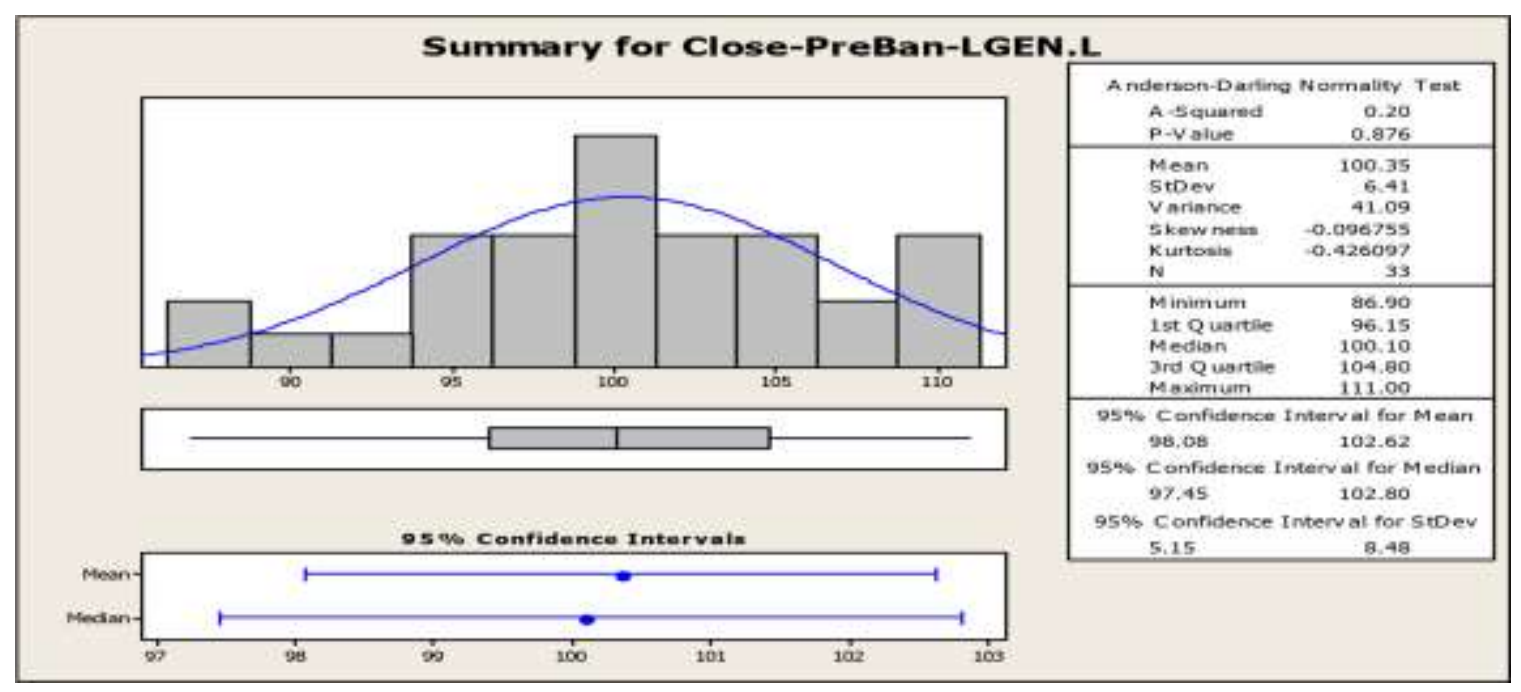

Fig:- 4.15 Summary of Pre Ban - Legal \& General

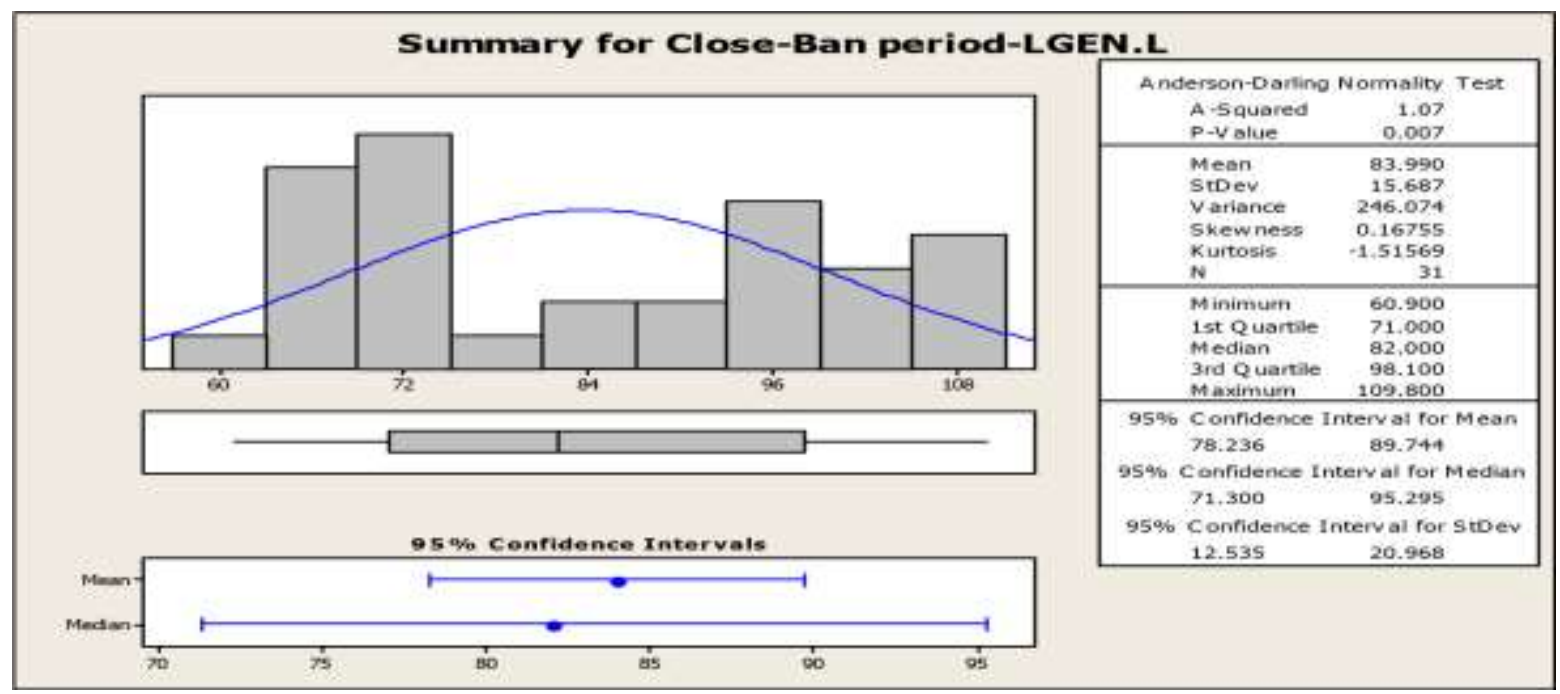

Fig:- 4.16 Summary of Ban period - Legal \& General

2468 | P a g e

w w w. cirworld. com

De ce m ber 2017

D O I : 10.24297/jssr.v11i3.6470 


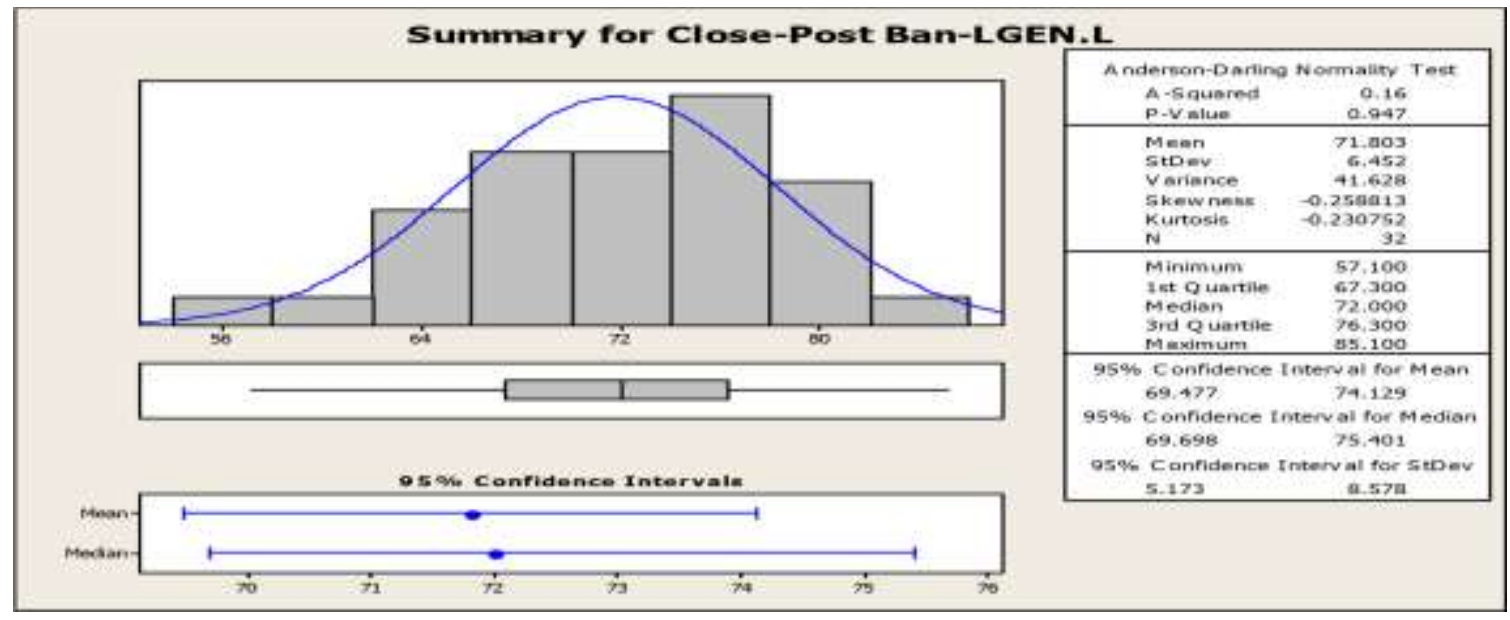

Fig:- 4.17 Summary of Post Ban - Legal \& General

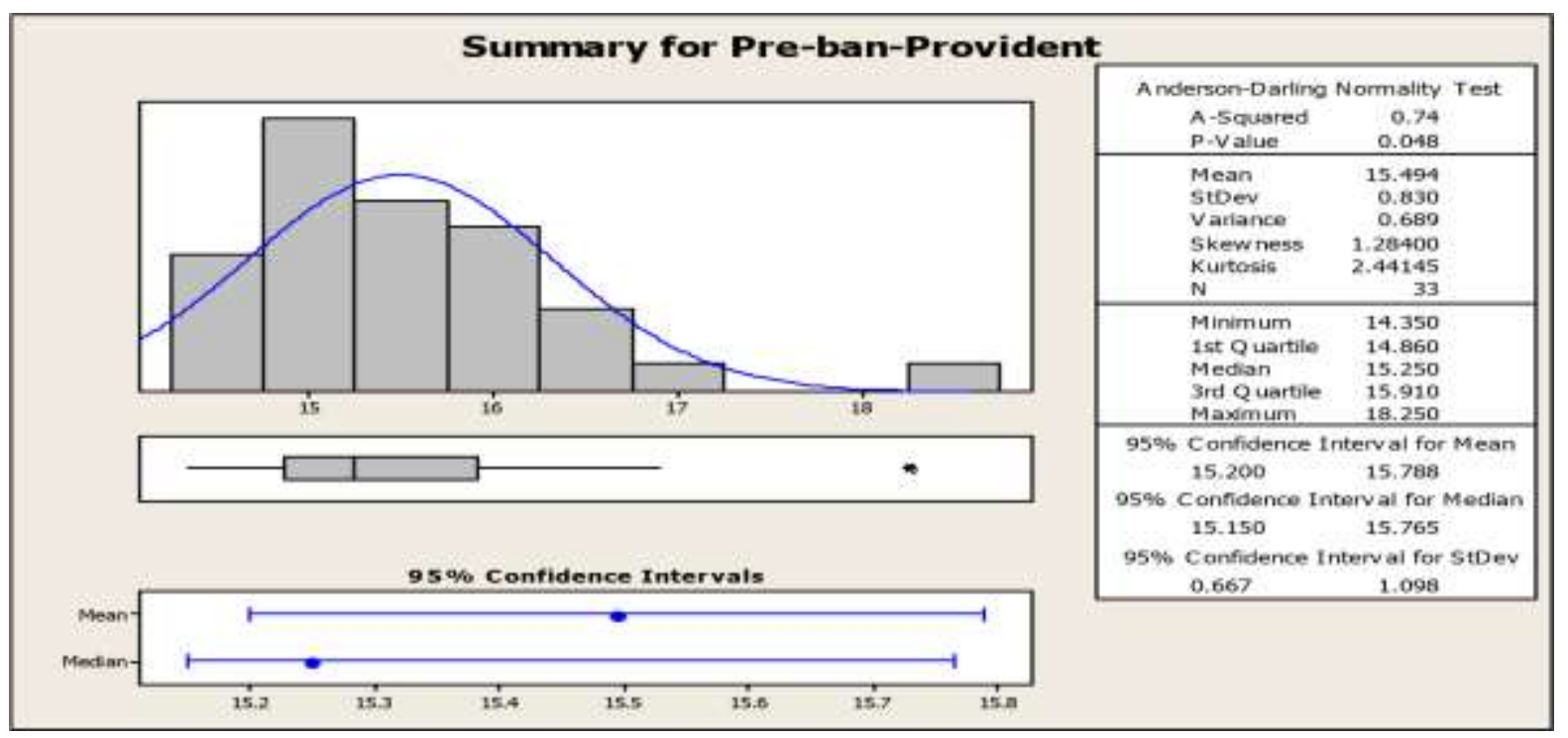

Fig:- 4.18 Summary of Pre Ban - Provident Financial Services

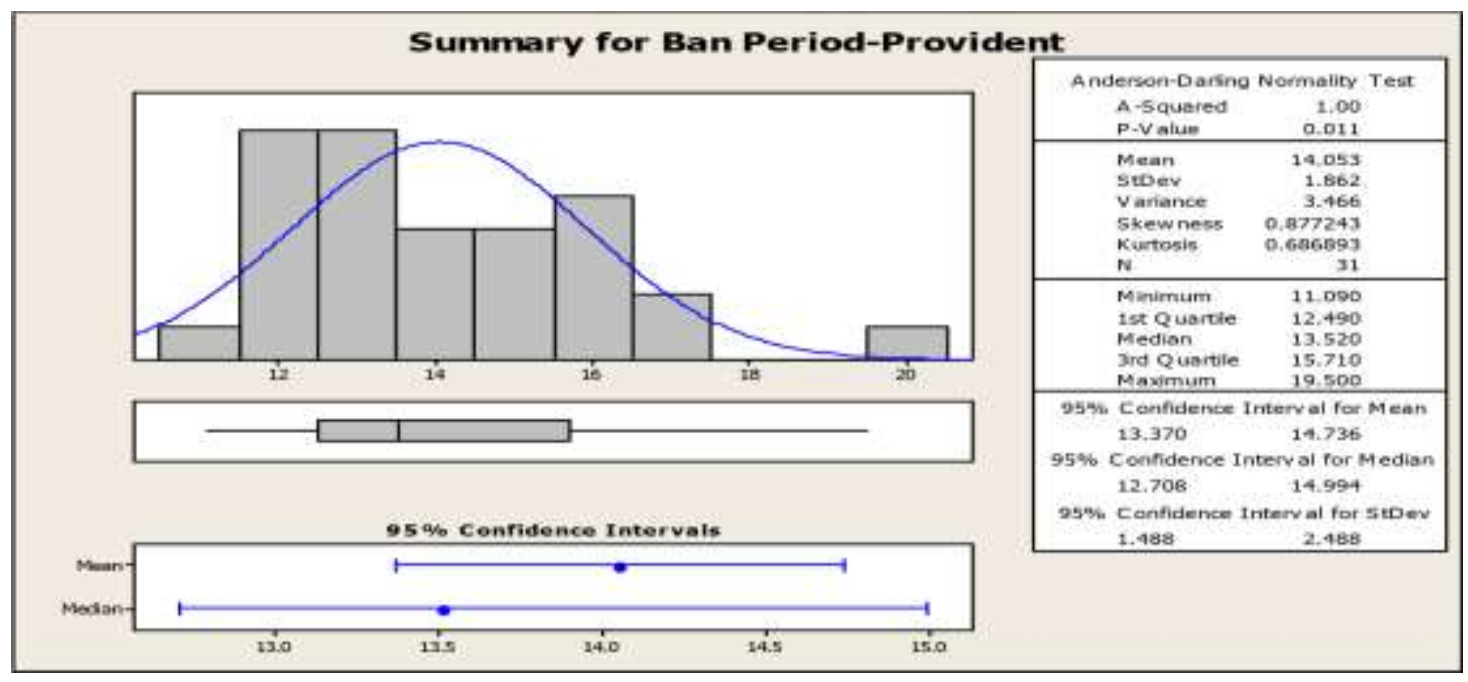

Fig:- 4.19 Summary of Ban period - Provident Financial Services 


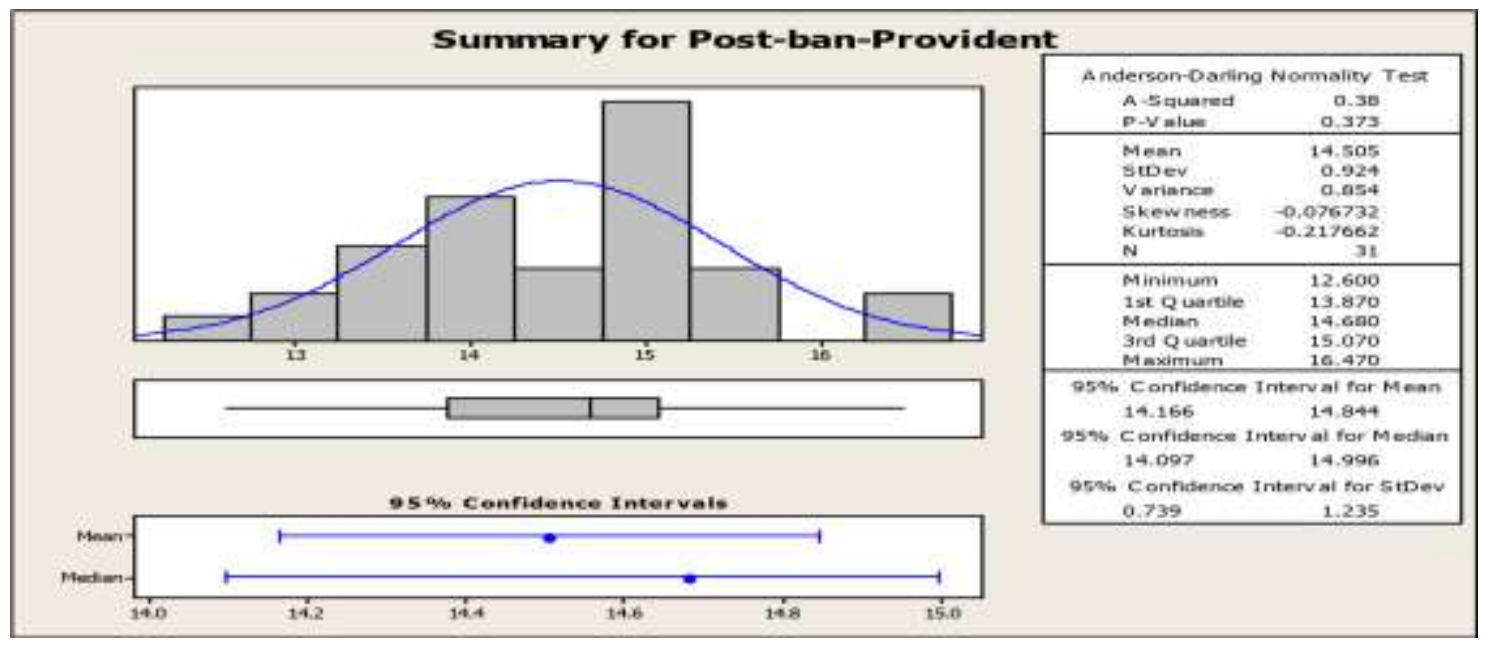

Fig:- 4.20 Summary of Post Ban - Provident Financial Services

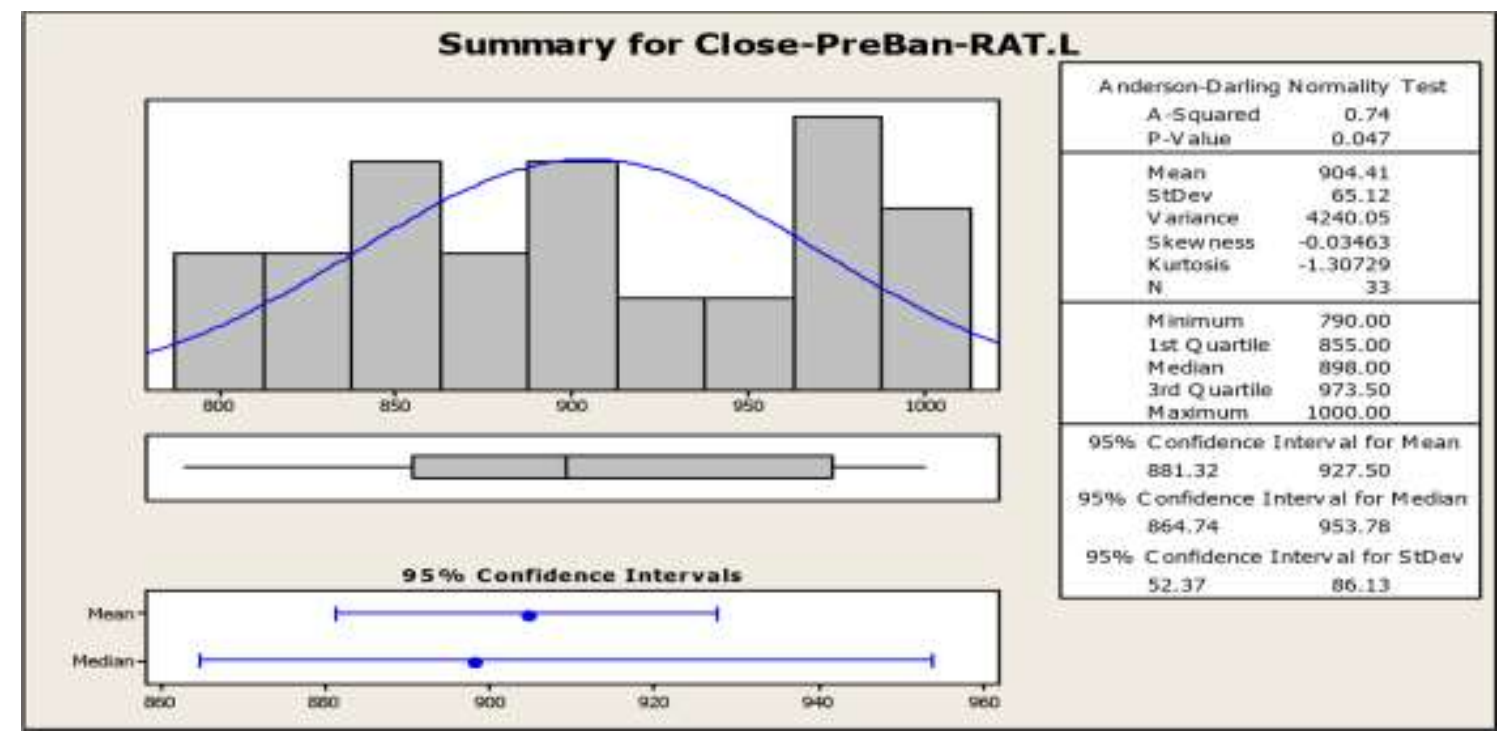

Fig:- 4.21 Summary of Pre Ban - Rathbone Brothers

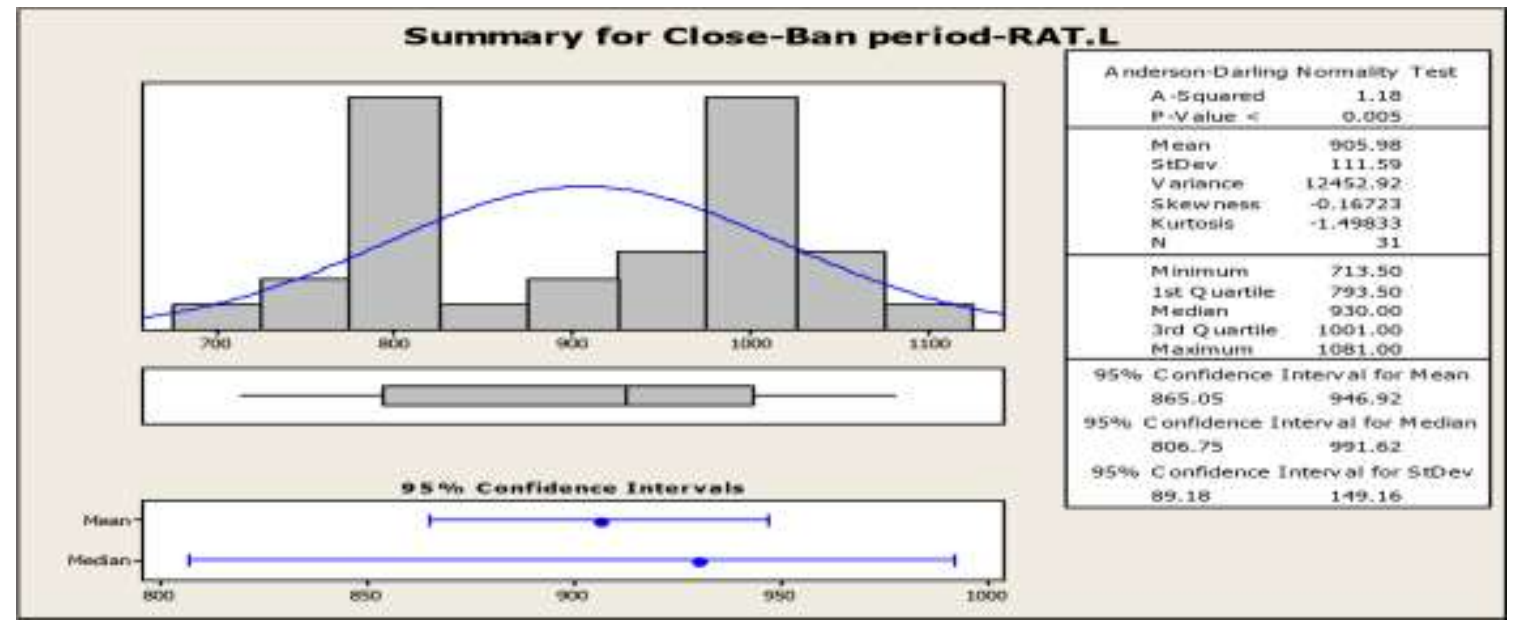

Fig:- 4.22 Summary of Ban period - Rathbone Brothers

$2470 \mid P$ a g e

w w w. cirworld. com

D e c e m ber 2017

D O I : 10.24297/jssr.v11i3.6470 


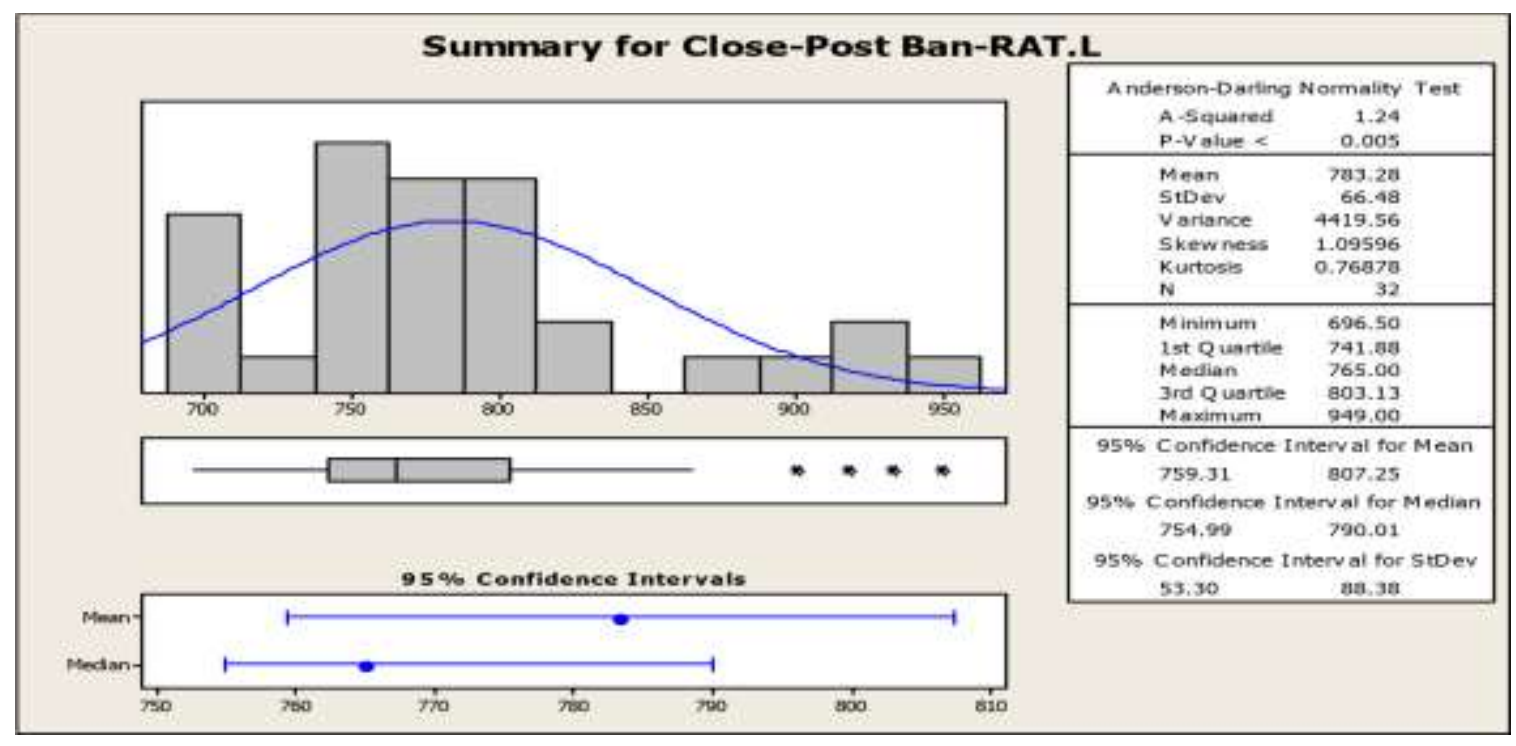

Fig:- 4.23 Summary of Post Ban - Rathbone Brothers

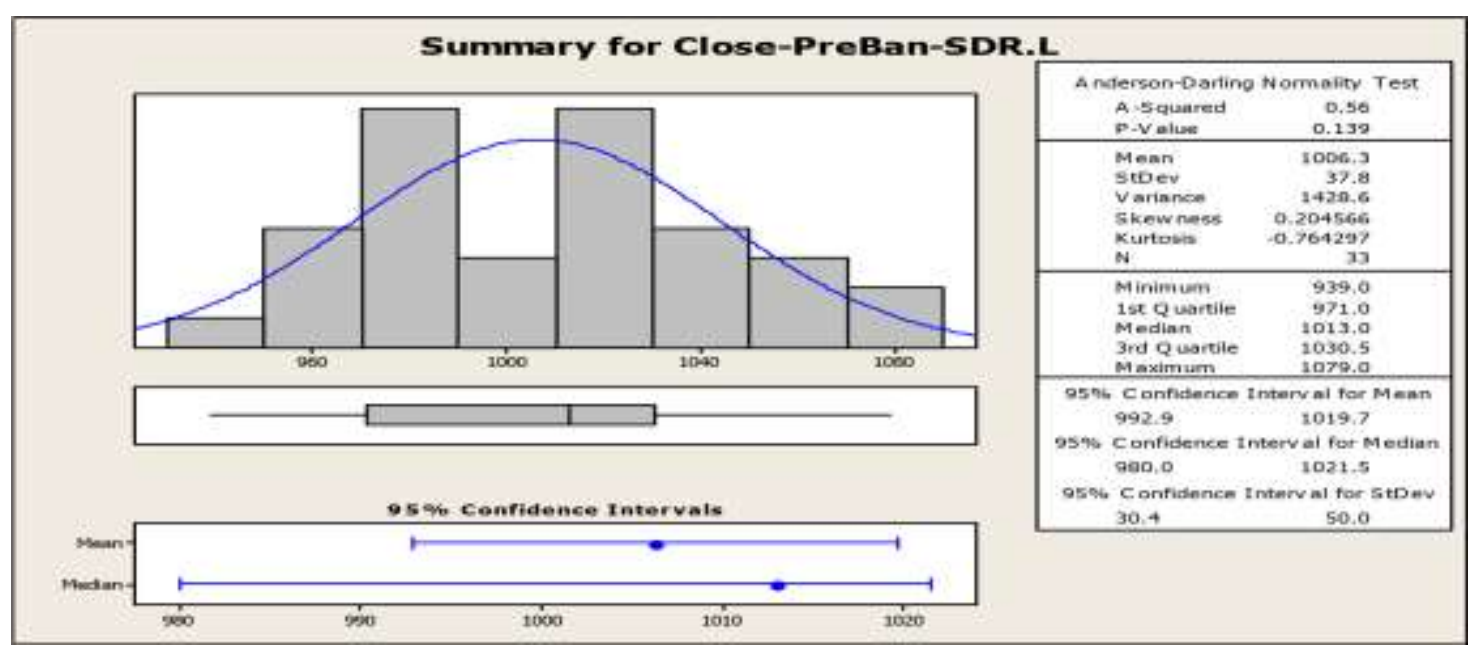

Fig:- 4.24 Summary of Pre Ban - Schroders

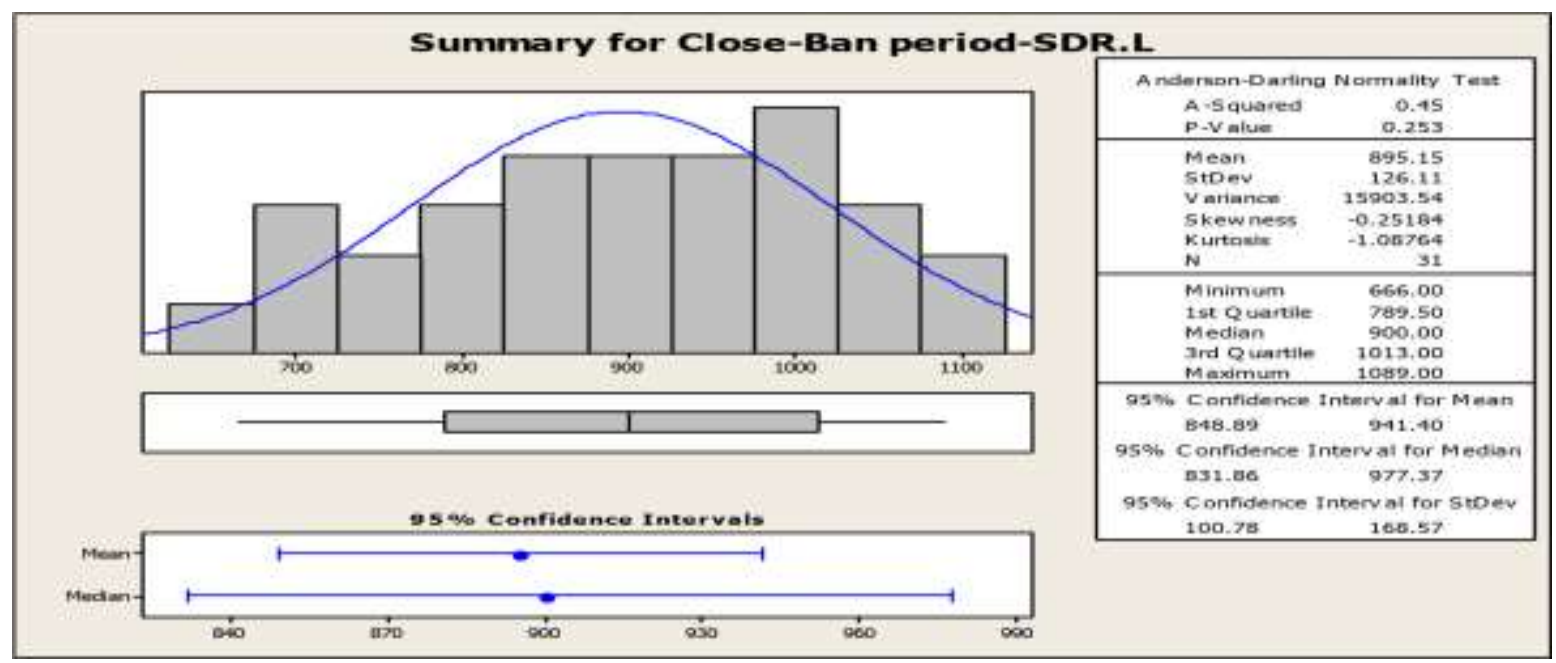

Fig:- 4.25 Summary of Ban period - Schroders

2471 | P a g e

w w w . cirworld. com

De ce m ber 2017

D O I : 10.24297/jssr.v11i3.6470 


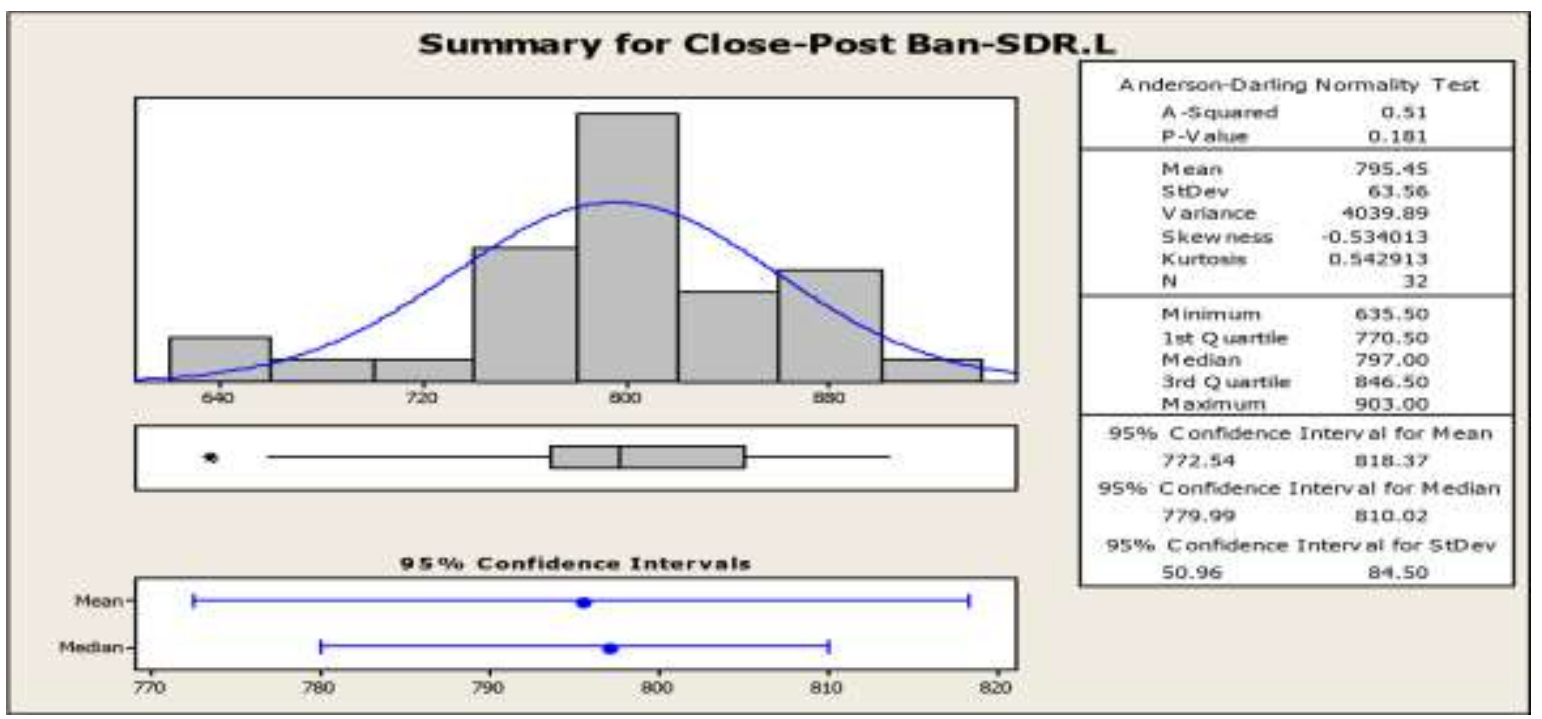

Fig:- 4.26 Summary of Post Ban - Schroders

\subsection{Inference from Measure of Central Tendency}

Since most of the data set is normally distributed the analysis of the measure of central tendency such as mean, median and mode will give a thorough insight about the data. Examining the graphical summary listed in the figures 4.3 to 4.26 the following inferences can be drawn out. The interesting pattern about the statistical variants of the observed eight sets of data is that the standard deviation is higher in the ban period for all the eight stocks. The differences in standard deviation of these eight stocks are significant varying more than $70 \%$ to $400 \%$ during the ban period compared to the pre-ban period and post ban period. It should be noted that the stocks started declining immediately after the fall of Lehmann brothers which happened on $8^{\text {th }}$ September 2008 ,

i.e in the immediate prerestriction period. Till $19^{\text {th }}$ September there was no ban or any restrictions and the market was trading as free as ever. There was obvious slide in shares during this period and the trend persisted even after the ban was announced. It can be inferred that the ban did not have any effect to stop the sliding pattern; neither had it helped to slow down the pace of the slide. It should be noted that the highest single day loss in stock value of all the eight stocks during the immediate prerestriction period and the ban period are very much comparable. We can observe that most stocks including the unrestricted stocks listed in UK tend to follow the same pattern. The mean values of the eight stocks also slided similarly in all the three phases considered, irrespective of the ban.Further, the volatility was higher for all the stocks during the ban period which can be illustrated from the table 4.5. During the ban period the range of stock value was enormously higher than the pre-ban and the post-ban. One should keep in mind the fact that the selling pressure was huge in the immediate pre-restriction period. The opponents of short selling argued that the selling pressure is due to the role of short sellers and this argument can be rejected completely by thoroughly observing the trend indicated in the comparison of range and median. The stock values of these restricted stocks fluctuated enormously from $100 \%$ to $900 \%$ approximately in the ban period against the same in the post-ban and pre-ban. The comparison between the range of all stocks in the pre-ban and the post-ban period indicates the fact that without any short selling restrictions the market behaved in a less unstable and less volatile manner.

\begin{tabular}{|l|r|r|r|r|r|r|}
\hline & \multicolumn{2}{|c|}{ Pre-Ban } & \multicolumn{2}{c|}{ Ban period } & \multicolumn{2}{c|}{ Post-Ban } \\
\hline STOCKS & RANGE & MEDIAN & RANGE & MEDIAN & RANGE & MEDIAN \\
\hline ATST.L & 45 & 311 & 90 & 252.75 & 43.5 & 248 \\
\hline AVIVA & 92.5 & 519 & 319.75 & 417 & 128.25 & 379.38 \\
\hline BARCLAYS & 78.5 & 346.5 & 210.1 & 242.5 & 68.2 & 157.95 \\
\hline INVP.L & 116 & 375 & 161.5 & 265.5 & 88.5 & 258.75 \\
\hline GEN.L & 24.1 & 100.1 & 48.9 & 82 & 28 & 72 \\
\hline PROVIDENT & 3.9 & 15.25 & 8.41 & 13.52 & 3.87 & 14.68 \\
\hline RAT.L & 210 & 898 & 367.5 & 930 & 252.5 & 765 \\
\hline SDR.L & 140 & 1013 & 423 & 900 & 267.5 & 797 \\
\hline
\end{tabular}




\section{Table 4.5 Comparison of range \& median}

\begin{tabular}{|l|l|l|l|l|l|l|l|l|l|}
\hline PERIOD & $\begin{array}{l}\text { Statistical } \\
\text { measure }\end{array}$ & $\begin{array}{l}\text { Volume- } \\
\text { ATST.L }\end{array}$ & $\begin{array}{l}\text { Volume- } \\
\text { AVIVA }\end{array}$ & $\begin{array}{l}\text { Volume- } \\
\text { BARCLAYS }\end{array}$ & $\begin{array}{l}\text { Volume- } \\
\text { INVP.L }\end{array}$ & VolumeLGEN.L & $\begin{array}{l}\text { Volume- } \\
\text { PROVIDENT }\end{array}$ & $\begin{array}{l}\text { Volume- } \\
\text { RAT.L }\end{array}$ & $\begin{array}{l}\text { Volume- } \\
\text { SDR.L }\end{array}$ \\
\hline
\end{tabular}

Therefore, it can be inferred beyond doubt that the temporary ban does not help the stocks in recovery during an economic meltdown situation. Hence the research hypothesis $\mathrm{RH} 3$, "The temporary and partial ban on short selling does not help the market to recover at times of economic meltdown" can be accepted.

Before we conclude on the research hypothesis $\mathrm{RH} 4$, a comparative study of the stock price movement of the eight stocks in terms of percentage is captured in the table 4.6. The percentage change values are made considering the closing price at the start and end date of each of the three phases: Pre-Ban period, Ban period and the PostBan period. Keeping the above discussion in mind, let us check each of the stocks price variations. We can see that in the pre-ban period and post ban period all stocks except Provident financial services and Rathbone Brothers have a downward movement. It should be inferred that most of the stocks were on a loosing trend in line with the major stock indices in UK. Meanwhile, in the ban period all the stocks were on a negative rally ranging from $20 \%$ to $54 \%$. This means that all the stocks their value by one fifth to half. This pattern significantly reflects the fact that the short selling ban does not cause excessive fluctuation in price and helps in improving the market efficiency. The feeling, I as a researcher is that the short selling ban did affect the efficient functioning of the market. Hence the research hypothesis RH4 "Since short selling is one of the few market forces in the complex financial market; short selling, acting as alone, does not cause excessive fluctuations of the prices of securities." is accepted.

\begin{tabular}{|l|c|c|c|c|c|l|l|l|}
\hline & $\begin{array}{l}\text { ALLIANC } \\
\text { TRUST }\end{array}$ & $\begin{array}{l}\text { AVIV } \\
\text { A }\end{array}$ & $\begin{array}{l}\text { BARCLAY } \\
\text { S }\end{array}$ & $\begin{array}{l}\text { INVESTE } \\
\text { C }\end{array}$ & $\begin{array}{l}\text { LEGAL \& } \\
\text { LERE }\end{array}$ & $\begin{array}{l}\text { RATHBON } \\
\text { EROVIDEN } \\
\text { TROTHER } \\
\text { BRCHRODER } \\
\text { S }\end{array}$ & $\begin{array}{l}\text { SCHR } \\
\text { S }\end{array}$ \\
\hline $\begin{array}{l}\text { POST- } \\
\text { BAN }\end{array}$ & $6 \%$ & $0 \%$ & $-16 \%$ & $-12 \%$ & $-2 \%$ & $-5 \%$ & $18 \%$ & $5 \%$ \\
\hline $\begin{array}{l}\text { BAN } \\
\text { PERIO } \\
\text { DE }\end{array}$ & $-20 \%$ & $-35 \%$ & $-54 \%$ & $-36 \%$ & $-33 \%$ & $-25 \%$ & $-26 \%$ & $-27 \%$ \\
\hline $\begin{array}{l}\text { PRE- } \\
\text { BAN }\end{array}$ & $-8 \%$ & $-3 \%$ & $-11 \%$ & $-13 \%$ & $-10 \%$ & $25 \%$ & $25 \%$ & $0 \%$ \\
\hline
\end{tabular}

\section{Table 4.6 Change of stock value in percentage}

Hence the research hypothesis $\mathrm{RH} 3$ and $\mathrm{RH} 4$ are accepted based on the explanation and statistics given above.

In the analysis of the volume of trade in the three different time period, the daily volumes of trade of all the eight stocks are captured. All the data is downloaded from the Yahoo Finance since it is reliable and directly in line with the data available in the stock exchanges. As we have done previously the periods are classified into three different zones: pre-ban, ban period and post-ban period. The mean, mode and the standard deviation of the eight stocks spread across three different time periods are calculated which is listed in table 4.7. 


\begin{tabular}{|c|c|c|c|c|c|c|c|c|c|}
\hline \multirow{3}{*}{$\begin{array}{l}\text { POST } \\
\text { BAN }\end{array}$} & mean & 2597165.6 & 7561087.5 & 51526094 & 1344093.8 & 13232947 & 641151.61 & 42431.25 & 295750 \\
\hline & median & 1686700 & 7068050 & 45948750 & 1123450 & 12906800 & 627500 & 30400 & 247850 \\
\hline & std.dev & 3702791.1 & 2227892.1 & 22436112 & 601906.42 & 3934918.9 & 168203.95 & 35718.22 & 186931.36 \\
\hline \multirow{3}{*}{$\begin{array}{c}\text { BAN- } \\
\text { PERIOD }\end{array}$} & mean & 2087345.2 & 12150774 & 59600023 & 2535129 & 20149048 & 662238.71 & 62803.226 & 490141.94 \\
\hline & median & 1990300 & 10258000 & 50754500 & 1922700 & 18457600 & 598400 & 42100 & 434600 \\
\hline & std.dev & 1139820.6 & 5789645.6 & 37280089 & 1732587.3 & 10720127 & 287932.03 & 67562.364 & 292491.23 \\
\hline \multirow{3}{*}{$\begin{array}{l}\text { PRE- } \\
\text { BAN }\end{array}$} & mean & 924778.79 & 10590639 & 84642509 & 3200930.3 & 32997227 & 774424.24 & 69912.121 & 884045.45 \\
\hline & median & 846500 & 9282300 & 65190100 & 2694300 & 28063000 & 691000 & 45000 & 770300 \\
\hline & std.dev & 541108.82 & 5098657.7 & 58857737 & 2041586.7 & 15941210 & 323334.36 & 58690.825 & 428352.93 \\
\hline
\end{tabular}

\section{Table 4.7: Comparison of volume of stocks of trading}

Except in the cases of ATST.L and AVIVA all the stocks tend to follow a certain pattern. Volumes of all the other stocks tend to get declined from the pre-ban period to post-ban period through the ban-period. This is a clear indication that the investors lost confidence in investing these periods. On an average, the volume of trading declined approximately $50 \%$ in these 135 calendar days. The mean and the median values of volume follow exactly similar patterns for all the stocks in all periods. The logical reason for considering both the mean and median is that the high values in a sample can literally disturb the mean value and the mean value may shift to higher value than expected. Moreover, median being the middle most value provides a vital insight into the nature of data. It should be specifically noted that the possibility of outliers in the mean value preparation is absolutely eliminated. All the data are processed through Minitab-15 which has identified the outliers and calculated mean value absolutely represents the true nature of the sample. From the table, the inference derived is that the investors had been panic in the period and started abstaining from the trading as the financial crisis deepened. The significant finding from the table is that the short selling ban as such did not help to boost the confidence level of investors. Despite the ban the volume of trading was getting low as days progressed. The exceptions in these periods were the Alliance Trust and Aviva; since the nature of business of both is similar there should be some other reason behind such a trend. Moreover the trading volumes got increased at each level for these two stocks. Since the scope of study is restricted, I keep this pattern unexplained and refer other interested researchers to investigate on this. Another vital piece of information which can be implied is that the standard deviations of these stocks tend to be lower at each stage from the pre ban to the post ban period. The noticeable factor is the stability of the amount of trading participants in the ban-period and post ban period. Hence the volatility in volume was lesser in these periods and the major reason may be the amount of money investors has lost after the Lehmann Brothers collapsed. This clearly indicates that the ban on short selling and the lifting of ban did not attract investors to trade. In addition to that the ban on short selling was wastage of exercise which did not yield the expectations of the opponents of short selling. Therefore, the argument that the ban on short selling motivates more investors to invest is disclaimed. Hence the research hypothesis RH5 "Trading volume went up after the ban since more investors can trade freely without the fear of short selling effects." is rejected based on the above explanation.

\subsection{Findings on the research question RQ6}

In the research, primary data has been collected to tackle this particular research question. A questionnaire has been distributed among 120 participants; all belong to the field of investments which include academically brilliant people to day-today traders to share-brokers. Out of 120 participants, 55 persons had participated in the exercise. The possible reason for such high turn around is the selection of participants, many of whom are direct contacts of the researcher.

\subsubsection{Analysis of data}

The questionnaire consisted of four questions and all are closed end questions. Apart from this, all were requested to give comments and viewpoints about short selling. Only 14 participants were ready to provide the comments. The comments provided by the participants are given due respect in the whole study and considered in making judgments. The basic reason behind going for such a primary data collection is that the entire capital market is highly illusive. The human perceptions, emotions and viewpoints play a major role in the stock price movements. Hence it is sensible to account the views of people who are associated with the capital markets. 


\subsubsection{Observation \& Inference}

The response of the participants in this survey is captured in the table 4.8. Further the data is analysed using the PieChart (fig:- 4.27). Let us examine each of the questions. The question Q1 was regarding the scrutinising of financial statements by short sellers. Nearly $56 \%$ responded that the short sellers normally scrutinise the possibility of any loopholes or accounting irregularities in the financial statements. Most shared the view that they help in finding the financial scandals. The motivation behind is that once a financial scandal is erupted there is every chance that the company will loose the shareholders trust which will cause a decline in the stock value.

\begin{tabular}{|l|l|l|l|}
\hline & Question & $\begin{array}{l}\text { No. of } \\
\text { yes }\end{array}$ & $\begin{array}{l}\text { No. of } \\
\text { No }\end{array}$ \\
\hline Q1 & Q1. Do short sellers scrutinise the companies' financial statements? & 31 & 24 \\
\hline Q2 & $\begin{array}{l}\text { Q2. Are there instances where the short sellers predicted possible downfall of } \\
\text { companies due to scandals? }\end{array}$ & 44 \\
\hline Q3 & $\begin{array}{l}\text { Q3. Do the short sellers scrutinise and blacklist the companies which are } \\
\text { prone to financial fraudulent? }\end{array}$ & 11 \\
\hline Q4 & $\begin{array}{l}\text { Q4. Can the short sellers always predict suspicious } \\
\text { companies? }\end{array}$ & 39 \\
\hline
\end{tabular}

Table 4.8 Response of participants

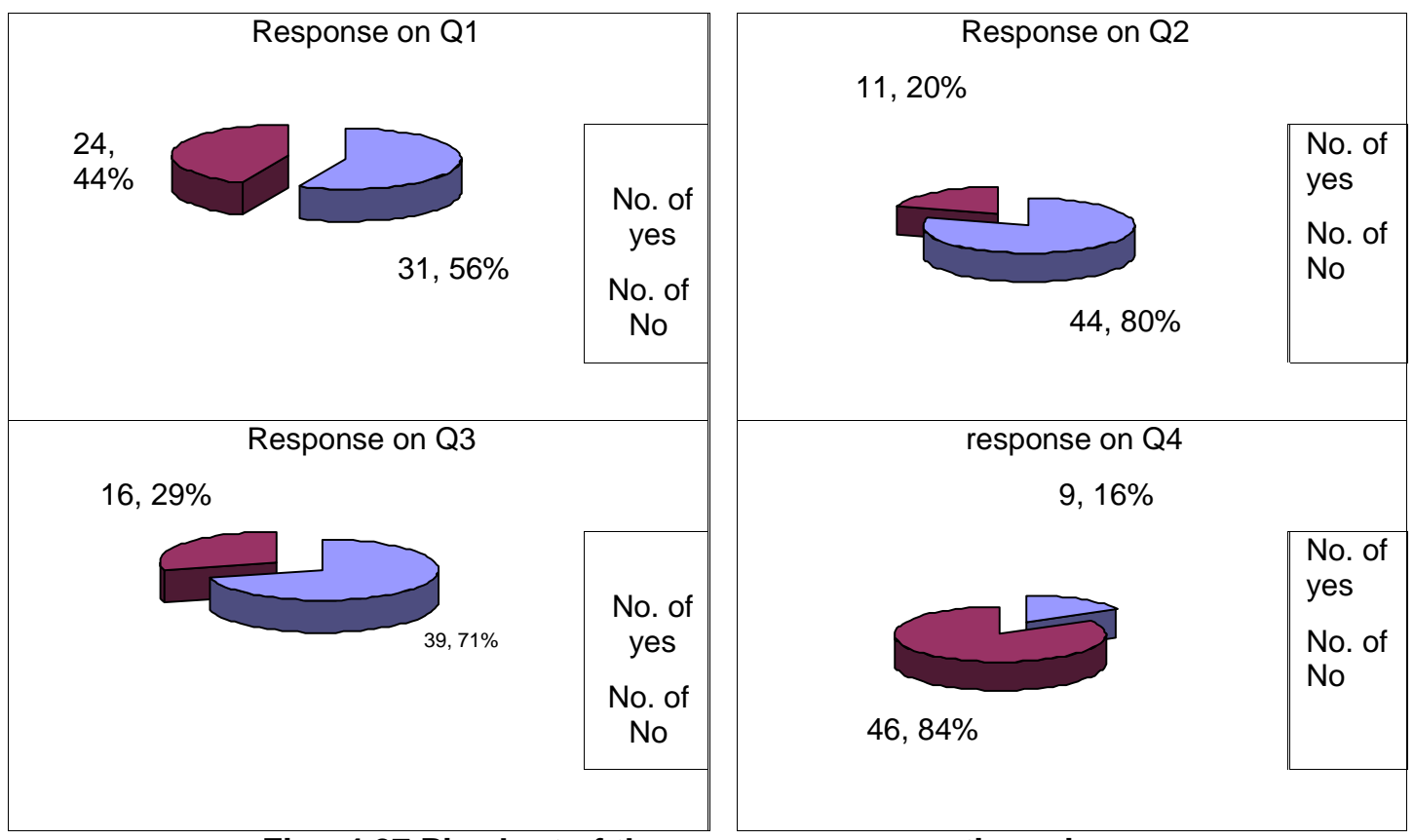

Fig:- 4.27 Pie chart of the response on questionnaire

Regarding the question Q2, $80 \%$ of the participants believed that there were numerous instances where short sellers smelt of possible financial irregularities. The typical examples of these cases are the Enron and the Worldcom debacle in the New York stock exchange. The third question Q3 infact revealed one of the smart strategies most of the short selling proponents follow. The survey revealed that they always shortlist some of the companies where financial control

2475 | $P$ a g e 
system and the internal audit system are not sound. Often this short listing helps the companies to be aware that they are prone to such accounting scandals. Finally the last question Q4 was regarding the extent of success of the short sellers in finding the fraudulence in companies. A vast majority of $84 \%$ opined that they cannot always find the companies where financial fraudulent are occurring. We can infer that the short sellers may not be successful as a precise watchdog. The major reason is that most of the fraudulent occur even after the internal and external audits and close monitoring by the regulatory bodies. Therefore, we can infer that the short sellers do scrutinise the possible errant companies though they may not be successful always.Based on the above explanations we can conclude that the research hypothesis "Short sellers scrutinise the financial statements of companies and can expose instances of financial fraudulent." can be accepted.

\begin{tabular}{|l|l|}
\hline \multicolumn{1}{|c|}{ Research Hypothesis } & Accept/Reject \\
\hline $\begin{array}{l}\mathrm{RH} 1 \text {. The short selling does play a major role in price discovery mechanism of } \\
\text { different scripts }\end{array}$ & Accepted \\
\hline $\begin{array}{l}\text { RH2. Short selling is a key criterion which helps in balancing the bullishness of } \\
\text { the financial markets and improves the market efficiency. }\end{array}$ & Accepted \\
\hline $\begin{array}{l}\text { RH3. The temporary and partial ban on short selling does not help the market to } \\
\text { recover at times of economic meltdown. }\end{array}$ & Accepted \\
\hline $\begin{array}{l}\text { RH4. Since short selling is one of the few market forces in the complex financial } \\
\text { market; short selling, acting as alone, does not cause excessive fluctuations of } \\
\text { the prices of securities. }\end{array}$ & Accepted \\
\hline $\begin{array}{l}\text { RH5. Trading volume went up after the ban since more investors can trade freely } \\
\text { without the fear of short selling effects. }\end{array}$ & Rejected \\
\hline $\begin{array}{l}\text { RH6. Short sellers scrutinise the financial statements of companies and can } \\
\text { expose instances of financial fraudulent. }\end{array}$ & Accepted \\
\hline
\end{tabular}

\section{Fig 4.9:- Overall findings on the research}

\subsection{Summary}

In this chapter the researcher discussed the findings and interpreted the results from the data collected. From the research it would possible to analyze various aspects regarding the short selling and the restrictions made on it. The research hypotheses were answered in this section and in the last table 4.9 of the chapter the researcher discussed the overall findings from the data. Based on these discussions suggestions or recommendations will be explained in the next chapter.

\section{CHAPTER 5 CONCLUSION \& RECOMMENDATIONS}

\subsection{Introduction}

This chapter provides a summary of the study's results based on the findings explained in chapter 4 in relation to the research problems, questions and hypothesis explained in the first chapter. Based on this specific conclusions are presented. Further the limitations of the research are listed, followed by recommendations for future research.

\subsection{Summary of findings and results}

In the last chapter the major findings of the research is listed in the table 4.9 based on the research hypothesis. Five of the six hypotheses were accepted. It is important to notice some of the key findings. The research was started following the debacle on short selling and its ban after the sub-prime crisis. Once Lehmann brothers collapsed, the blame game started and all the sin were dumped into the head of short selling. Hence it was important to know about the aspects of short selling and the tremors it can cause in the capital markets. The research was approached based on the logic that the short selling is not the only factor which caused the financial tremors. A thorough investigation has been done on the short selling and its effects. The study also aimed in finding some of the key advantages of retaining short selling in a market. Apart from this the study also aimed to find the negative effects of short selling. It was proved beyond doubt that the short selling does not accelerate the decline of sliding stocks. Moreover, for the efficient functioning of the market the existence of short selling is required. In addition to that, the ban on short selling did not have any serious positive impact on the confidence level of investors. Rather it created confusion and chaos among the investors. The obvious question of 'when the short selling restriction be lifted' during the ban period created widespread speculation. The study also justified the effect of short selling in the price discovery mechanism and it also
2476 | P a g e 
showed that it is nearly impossible to predict that how much it helped in discovering the price. The primary reason behind this is that at different stages different factors will have varying weightage in the discovery the price.

In otherwords, predicting a certain weightage of short selling in the price discovery mechanism is impossible.

\subsection{Limitations of the study}

There have been lots of obstacles and limitations in conducting the research program. One of the main limitations of the study is that in the research analysis of short selling impacts, the micro economic and other specific or unique factors affecting the market conditions are not considered. The time constraint in the study was another major limitation. Ideally the study would have been comprehensive if further research about the peculiar movements in the volumes of trading has been done, especially the cases of Alliance Trust and Aviva. Since the physical proximity with the UK markets were literally limited, further investigations into the reasoning behind the restrictions of short selling by the regulatory bodies could not be done. The major limitation in the whole study was the lack of access to confidential information; to be specific the study would have been much better if the volume of short selling was known to the public. Apart from that the cost constraint in purchasing the data through other channels was high. Another important limitation was the constraint regarding the scope and depth of the study. The study could not be extended a large number of stocks which might have made the whole dissertation look bulky.

\subsection{Recommendation}

The main recommendation for future studies is that the study can be done for an extended period. The current research study has just focussed on the short period of 135 days. An extended study for longer period with the considerations of all the instances of short selling ban should be done to make a solid judgement. The current study exclusively focussed on the short selling ban happened in 2008. The second recommendation regarding further study is that the peculiar movements of the volumes of trading of Alliance Trust and Aviva. Interestingly, the volumes of trading of these stocks increase during the pre-ban, ban and post ban period. Similarly, other stocks which are similar in nature may be there in the pool of the restricted stocks. Finding these stocks and reasons behind such a trend should be analysed and the researcher feels that it is worth investing time and money behind that. This may further discover some interesting insights regarding short selling. The third recommendation is that the study should be extended and done with the microeconomic considerations. The short selling weightage in the price discovery mechanism in special circumstances can be calculated in this way. Finally, there has been scarcity in terms of the academic research on short selling. Further comprehensive studies on different markets will provide a thorough conclusion on short selling impacts and it's after effects.

\subsection{Conclusion}

The research has given light to certain dark areas of short selling. The wrong perceptions or negative impression on short selling are corrected after a thorough study on the short selling. The research helped to evaluate and make judicious judgments about short selling and the related functioning in the market. The problems, issues, the scope etc were analysed in detail in the report. The insights and viewpoints put forwarded by the experts from field helped to acquire further knowledge about the strategies and complexity prevailing in the market. In the report, the chapter 1 discusses about the history and background of short selling. The controversial debate and the mechanisms of short selling were detailed in the chapter. The chapter 2 explained about the introductory concepts of trading and investments. The short selling debate and the academic research on short selling were discussed. The 3rd chapter discusses the research methodology the researcher planned to pursue. The data collection methods etc were described in the chapter which gave an idea of how the researcher would go about the entire research process. In fourth chapter all the research hypothesis were tested. Five of the six hypotheses were accepted and one was rejected. In the final chapter the recommendations and future scope of study is discussed.

\section{REFERENCE:}

1. "Short sellers have been the villain for 400 years" by Daniel Trotta, Retrieved on March 6, 2009 from http://www.reuters.com/article/reutersEdge/idUSTRE48P7CS20080926?PageNu $\underline{\text { mber }=2 \& \text { virtualBrandChannel }=0 \& s p=\text { true }}$

2. "UPDATE 1-UK's FSA-short selling not behind share price falls" on January 22 2009, Retrieved on March 62009 from http://uk.reuters.com/article/UK COMKTNEWS/idUKLM06105020090122

3. "A Brief History Of Short Selling By CLAIRE SUDDATH" on September 22 2008, Retrieved on March 72009 from http://www.time.com/time/business/article/0,8599,1843255,00.html

4. The history of short selling rule By Daniel at 8 April, 2009, Retrieved on April 102009 from http://investment-blog.net/the-history-of-short-selling-rule/ 
5. http://www.theherald.co.uk/features/letters/display.var.2455782.0.Brief_history_o f_short_selling_shows_banks_have_learned_nothing.php

6. Fabozzi Frank(2004), Short Selling-Strategies, Risks and Rewards, John Wiley and sons

7. Claire Suddath, "A Brief History of Short Selling" Sep. 22, 2008 from http://www.time.com/time/business/article/0,8599,1843255,00.html, Retrieved on April 52009

8. Bob Litterman, "The Active Risk Puzzle: Implications for the Asset Management Industry," The Active Alpha Investing Series (Goldman Sachs Asset Management, March 2004)

9. Sullivan, arthur; Steven M. Sheffrin (2003). Economics: Principles in action. Upper Saddle River,: Pearson Prentice Hall

10. Securities Lending Transactions: Market Development and Implications, Technical

11. Committee of the International Organization of Securities Commissions (July 1999).

12. Bargerhuff \& Associates, "Securities Lending Analytics" (2nd quarter, 2000).

13. Knepper, Zachary T (2004). "Future-Priced Convertible Securities \& The Outlook For "DeathSpiral" Securities-Fraud Litigation" (pdf). Bepress Legal Repository. Berkeley

14. Emshwiller, John R., and Kara Scannell (July 5, 2007). "Blame the 'Stock Vault'?". The Wall Street Journal. Retrieved on March $25 \quad 2009$ from http://online.wsj.com/public/article/SB1183598675629577205Yb1Y mpcl9a2nKbc0laV0tDHyk 20 $\underline{070712 . h t m l}$.

15. Ellis, David (September 17, 2008). "SEC puts 'naked' short sellers on notice". www.cnn.com. \begin{tabular}{lllll} 
Retrieved on & March & 30 & & \\
\cline { 2 - 3 } & & &
\end{tabular} http://money.cnn.com/2008/09/17/news/companies/sec short selling/index.htm.

16. "Key Points About Regulation SHO". Securities and Exchange Commission. April 11, 2005, Retrieved on April 102009 from http://www.sec.gov/spotlight/keyregshoissues.htm.

17. "Division of Market Regulation: Responses to Frequently Asked Questions Concerning Regulation SHO". Securities and Exchange Commission, Retrieved on April 102009 from http://sec.gov/divisions/marketreg/mrfaqregsho1204.htm.

18. Searching for the naked truth, The Economist, Aug 17, 2008, Retrieved on April 102009 from http://www.economist.com/businessfinance/PrinterFriendly.cfm?story id=119512 $46 \mathrm{x}$

19. Gordon, Marcy (2008-09-17). "SEC adopts rules against 'naked' short-selling". Associated Press, Retrieved on April 82009 from http://www.iht.com/articles/ap/2008/09/17/business/NA-US-SEC-ShortSelling.php.

20. Susan Christoffersen, Christopher Geczy, David Musto, and Adam Reed, "How and Why do Investors Trade Votes, and What Does it Mean?" working paper, Wharton School of Business, University of Pennsylvania, March 2004.

21. Gene D'Avolio, "The Market for Borrowing Stock," Journal of Financial Economics (November 2002), pp. 271-306.

22. D'Avolio, "The Market for Borrowing Stock" and Christopher Geczy, David Musto, and Adam Reed, "Stocks Are Special Too: An Analysis of the Equity

Lending Market," Journal of Financial Economics (November 2002), pp. 241-269

23. D'Avolio, "The Market for Borrowing Stock" and Christopher Geczy, David Musto, and Adam Reed, "Stocks Are Special Too: An Analysis of the Equity

Lending Market," Journal of Financial Economics (November 2002), pp. 241-269 
24. Paul Asquith and Lisa Meulbroek, "An Empirical Investigation of Short Interest," working paper, Harvard Business School, Harvard University, 1995.

25. D. Harmon and Y. Bar-Yam. "Technical Report on SEC Uptick Repeal Pilot". New England Complex Systems Institute, Retrieved on May 10 2009 from http://www.necsi.edu/research/UptickTechReport.pdf.

26. "Amendments to Exchange Act Rule 10a-1 and Rules 201 and $200(\mathrm{~g})$ of Regulation SHO". From SEC website http://www.sec.gov/divisions/marketreg/tmcompliance/rules10a200g-201secg.htm. Retrieved on 31-3-2009

27. Ackerman, Gary "Ackerman Urges New SEC Chief to Restore Uptick Rule to Regulate Short Sales of Stocks", on Retrieved on 2009-04-16 from http://www.house.gov/list/press/ny05_ackerman/PR_012709.html.

28. Bernanke: Uptick rule might have been useful during crisis". MarketWatch. Retrieved on 2009-0225. from http://www.marketwatch.com/news/story/bernanke-uptick-rulemighthave/story.aspx?guid=\{78BCD860-C835-4E71-821E-8FB62D7C7964\}.

29. Pessin, Alfred (1978). Fundamentals of the Securities Industry. New York Institute of Finance. p. 241 retrieved on 21-3-2009

30. Stock Price factors (image) (What affects stock prices? 2008) Retrieved on September 5, 2008 from http://www.howthemarketworks.com/populartopics/stock-price-factors.php

31. Manipulation, Retrieved on September $5, \quad 2008$ from http://www.investopedia.com/terms/m/manipulation.asp

32. New York Stock exchange, A guide to the NYSE market place, retrieved on September 5, 2008 from http://www.nyse.com/pdfs/nyse bluebook.pdf

33. First step to investing in the share market, Retrieved on September 52008 from http://www.sharekhan.com/

34. Wyss, B O'Neill Wyss(2001), Fundamentals of the stock market, McgrawHill,USA

35. Official website of London Stock Exchange, Retrieved on September 8, 2008, from http://www.londonstockexchange.com/en-gb/

36. Official Website of New York Stock Exchange, Retrieved on September 5, 2008, from http://www.nyse.com/

37. Economy watch, Retrieved on September 8, 2008 from http://www.economywatch.com/stockmarkets-in-world/

38. CFA Institute, CFA Level 1 program curriculum 2008 ,Volume 1, Pearson Custom Publishing, Boston

39. CFA Institute, CFA Level 1 program curriculum 2008, Volume 2 Pearson Custom Publishing, Boston

40. CFA Institute, CFA Level 1 program curriculum 2008, Volume 3 Pearson Custom Publishing, Boston

41. CFA Institute, CFA Level 1 program curriculum 2008, Volume 4 Pearson Custom Publishing, Boston

42. CFA Institute, CFA Level 1 program curriculum 2008, Volume 5 Pearson Custom Publishing, Boston

43. CFA Institute, CFA Level 1 program curriculum 2008, Volume 6 Pearson Custom Publishing, Boston 
44. Creswell, J.W. (2003) Research Design: Qualitative, Quantitative and Mixed Method Approaches. California: Sage Publications.

45. Saunders, Mark; Thornhill, Adrian; Lewis, Philip (2007) Research Methods for Business Students, $3^{\text {rd }}$ Edition, Prentice Hall

46. Jackson, P. (1994). Desk Research. London: Kegan-Paul.

47. Marcoulides, G. A. (1998) Modern Methods for Business Research. NY:

Lawrence Erlbaum Associates.

48. Miles, M.B. and Huberman, M. (1994) Qualitative Data Analysis: A Source Book of NewMethods. London: Sage Publications

49. Page and Meyer, (2000) Applied Research Design for Business and Management", McGrawHill

50. Hussey, J. \& Hussey, R. 1997, Business Research, Macmillan Press Ltd, Basingstoke.

51. Cooper D.R. \& Schindler P.S. (1998) 'Business Research Methods' Irwin, 6th Edition, 1998

52. Cooper H.M. (1998) 'Synthesizing Research, A Guide for Literature Reviews' Sage Publications, March 1998

53. Jankowicz, A.D. (2005) Business Research Projects, (4th Edition).

54. "Discussion paper on Short Selling and Securities Lending and Borrowing"(2008), by Secondary Market Advisory Committee of SEBI

55. Marsh,W. lan and Niemer, Norman (2008) The Impact of Short Sales Restrictions, Cass Business School

56. "More woes for Refco, execs: Newspapers say creditors eye over $\$ 1 \mathrm{~B}$ insiders made from stock, while SEC probes "naked shorting"'". CNN/Money. October 20,

2005, Retrieved on April $20 \quad 2009$ from http://money.cnn.com/2005/10/20/news/midcaps/refco/index.htm.

57. "SEC Complaint against Gryphon Partners" (PDF). December 12,2006, Retrieved on April 20 2009 from http://www.sec.gov/litigation/complaints/2006/comp19942.pdf.

58. "Goldman Sachs fined $\$ 2 \mathrm{~m}$ over short-selling". TimesOnline and AP. March 15, 2007. Retrieved on $\quad$ April $20 \quad 2009$ from http://business.timesonline.co.uk/tol/business/law/corporate/article1519648.ece.

59. "S.E.C. Requests Receiver for Universal Express". The New York Times. June 23, 2007. Retrieved on April 202009 from http://www.nytimes.com/2007/06/23/business/23sec.html.

60. Floyd Norris, "A Sad Tale of Fictional SEC Filings", The New York Times, June 22, 2007

61. "Monthly Disciplinary Actions - July 2007 ", NYSE Regulation, July 11, 2007

62. Edgar Ortega, "Piper Fined by the NYSE Over Short-Sale Violations", Bloomberg News, July 11, 2007

63. "SEC Charges New York Hedge Fund Adviser With Short Sale Violations in Connection With Hibernia-Capital One Merger", SEC Press Release, October 10, 2007

64. Heidi N. Moore, "We See Dead People: \$250K Fine for Lehman Short-Sales", Wall Street Journal, October 22, 2008

65. "DTCC response to Wall Street Journal Article", Press release, July 6, 2007

66. Kaja Whitehouse (2008-11-05). "Drop in naked shorts". New York Post. Retrieved on April 30 2009 from http://www.nypost.com/seven/11052008/business/drop_in_naked_shorts_137107. htm. 
67. James W. Christian, Robert Shapiro \& John-Paul Whalen (2006). "Naked Short Selling: How Exposed Are Investors?". Houston Law Review. Retrieved on May

112009 from http://www.houstonlawreview.org/archive/downloads/434_pdf/Christian.pdf.

68. Drummond, Bob (August 4, 2006). "'Naked Short Sellers Hurt Companies With Stock They Don't Have"'. Bloomberg.com. Retrieved on May $11 \quad 2009$ from http://www.rgm.com/articles/bloomberg2.html.

69. "DTCC Chief Spokesperson Denies Existence of Lawsuit". financialwire.net. May 11, 2004. Retrieved on May 112009 from http://www.rgm.com/articles/financialwire.html.

70. "Senator Bennett Discusses Naked Short Selling on the Senate Floor", website of Senator Bennett, July 20, 2007, Retrieved on May $11 \quad 2009$ from http://bennett.senate.gov/public/index.cfm? $p=$ Speeches\&ContentRecord_id=0c9d

7162-e177-459f-93cd-f3b51bdad7b5\&ContentType_id=245cad09-9482-4f0d-

8004-9c5ff620e986\&f1e77522-3fb1-4336-9ec8-fb7cc501dba0

71. "WayPoint Biomedical Holdings, Inc. Files Lawsuit Against The Depository

Trust and Clearing Corporation (DTCC)". Genetic Engineering and Biotech News. June 25, 2007. Retrieved on May 42009 from http://www.genengnews.com/news/bnitem.aspx?name=19497609.

72. "Nevada Court Dismisses Nanopierce Lawsuit Against DTCC On Naked Short

Selling". Depository Trust Clearing Corporation. May 2005. Retrieved on April 112009 from http://www.dtcc.com/Publications/dtcc/may05/nanopierce.html.

73. Moyer, Liz (2006-04-13). "Naked Shorts". Forbes. Retrieved on April 82009 from http://www.forbes.com/business/2006/04/13/naked-shorts-lawsuitcx_Im_0413naked.html.

74. "US Judge Dismisses Naked Short Selling Suit Vs. Brokers", Dow Jones News Service, Dec. 20, 2007

75. "Naked Short Victim Strikes Back". Forbes. February 2, 2007. Retrieved on May 262009 from http://www.forbes.com/2007/02/02/naked-short-suit-overstock-bizcx_Im_0202naked.html.

76. Liz Moyer (July 18, 2007). "Naked Shorting Case Gains Traction". Forbes.

Retrieved on May 142009 from http://www.forbes.com/wallstreet/2007/07/18/naked-shortingoverstock-bizwallst-cx_Im_0718overstock.html.

77. "Overstock Shares Rise on Court Ruling in Broker Suit", Bloomberg News, July 18, 2007

78. Pet Quarters, Inc. v. Depository Trust and Clearing Corp. --- F.3d ----, 2009 WL 579270 C.A.8 (Ark.),2009.

79. "Court Rules Against Company Claiming Illegal Short Selling" by Carol Remond, Dow Jones News Service, March 11, 2009

80. Companies in the Oil Business for the Long Haul by Giuseppe Marconi(2008) Retrieved on April 10 2009 from http://www.oil-price.net/

81. Profitability and $\$ 100$ oil by Steve Austin - 2008/01/05 Retrieved on April 102009 from http://www.oil-price.net/

82. Light Sweet Crude Oil(2008) Retrieved on May 252009 from http://www.nymex.com/lsco_fut_descri.aspx

83. Ajay Shah(1998), "The price discovery mechanism" Retrieved on April 72009 from http://www.mayin.org/ajayshah/MEDIA/1998/pricediscovery.html

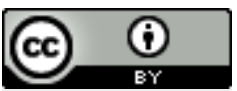

This work is licensed under a Creative Commons Attribution 4.0 International License 